\title{
Diferenças salariais e o impacto da segmentação regional: um estudo para os trabalhadores na cultura de cana-de-açúcar no período de 2012 e $2019^{1}$
}

\author{
Wage gap and the impact of regional segmentation: a study for \\ workers in the sugarcane culture in 2012 and 2019
}

Gabriela Gomes Mantovani [D, Pery Francisco Assis Shikida (D), Magno Rogério Gomes² (D)

1Programa de Pós-graduação em Desenvolvimento Regional e Agronegócio, Universidade Estadual do Oeste do Paraná (UNIOESTE), Toledo (PR), Brasil. E-mails: gmmantovani@gmail.com; peryshikida@hotmail.com

²Programa de Pós-graduação em Economia Aplicada, Universidade Estadual de Maringá (UEM), Maringá (PR), Brasil. E-mail: magnogomes@gmail.com

\begin{abstract}
Como citar: Mantovani, G. G., Shikida, P. F. A., Gomes, M. R. (2022). Diferenças salariais e o impacto da segmentação regional: um estudo para os trabalhadores na cultura de cana-de-açúcar no período de 2012 e 2019. Revista de
\end{abstract} Economia e Sociologia Rural, 60(1), e241167. https://doi.org/10.1590/1806-9479.2021.241167

Resumo: $O$ artigo visa identificar as desigualdades salariais dos trabalhadores inseridos na cultura de cana-de-açúcar nas macrorregiões produtoras Centro-Sul e Norte-Nordeste e mensurar suas causas para os hiatos salariais regionais. Utilizaram-se microdados da Pesquisa Nacional por Amostra de Domicílios Contínua (PNAD-C) para 2012 e 2019 e foram estimadas as regressões mincerianas e quantílicas com correção de viés de seleção amostral. Além disso, a decomposição contrafactual de salários de Oaxaca-Blinder também foi aplicada na média e nos quantis. Os resultados obtidos confirmaram a diferença de salários dos trabalhadores inseridos no cultivo de cana-de-açúcar entre as duas áreas selecionadas, caracterizando aqueles que trabalham no Centro-Sul como grupo em vantagem. O hiato salarial aumentou no período, sendo maior para os empregados com baixos rendimentos em 2012, enquanto, em 2019, a diferença foi superior para os trabalhadores com maiores remunerações. Constatou-se ainda que a segmentação regional é o grande motivador e responsável pela maior parte das desigualdades salariais em ambos os anos, secundarizando as características pessoais e produtivas do trabalhador.

Palavras-chave: diferenças salariais, segmentação regional, cana-de-açúcar, decomposição salarial.

Abstract: This study aims to identify the inequalities in wages of workers inserted in the culture of sugarcane in the producing macro-regions of South-Central and North-Northeast and to measure their causes for regional wage gaps. The microdata collected from the Continuous National Household Sample Survey (Continuous PNAD) of 2012 and 2019 were analyzed, and quantile/mincerian regression models with correction of sample selection bias were estimated. Furthermore, the counterfactual wage decomposition of Oaxaca-Blinder was also applied on the average and by quantiles. These results confirmed the difference in workers' wages between the two selected areas, characterizing those who work in the South-Central as an advantaged group. The wage gap increased in the period, which is greater for low-income employees in 2012, while in 2019, the difference was greater for workers with higher wages. Thus, it was possible to perceive that the regional segmentation is primarily responsible for most of the wage inequalities in both years, relegating the personal and productive characteristics of the worker.

Keywords: wage gap, regional segmentation, sugarcane, wage decomposition.

\section{INTRODUÇÃO}

A cultura da cana-de-açúcar é de grande importância para a economia brasileira e sua cadeia produtiva tem presença nos três grandes setores de produção, estando presente no

\footnotetext{
1 O presente trabalho foi realizado com o apoio do Conselho Nacional de Desenvolvimento Científico e Tecnológico Brasil (CNPq).
} 
consumo da população, no setor industrial no fornecimento de insumos - como alimentos, medicamentos, combustíveis - e na criação de empregos (Silva et al., 2006; Neves \& Conejero, 2007; Shikida \& Rissardi Júnior, 2017). De acordo com informações da Relação Anual de Informações Sociais (Brasil, 2017), em 2017 o setor sucroalcooleiro gerou aproximadamente cerca de 409 mil postos de trabalhos formais, sendo considerados os trabalhadores formais dos setores do cultivo de cana-de-açúcar, fabricação de açúcar bruto, açúcar de cana refinado e de aguardente. Outrossim, em estimativa do produto interno bruto (PIB) da cadeia produtiva da cana (composta dos segmentos de insumos, atividades primárias/produção agrícola, indústria e serviços/transporte e comércio), realizada pelo Centro de Estudos Avançados em Economia Aplicada (Centro de Estudos Avançados em Economia Aplicada, 2017), foi obtido o valor de R $\$ 156$ bilhões em 2017, o segundo maior PIB do agronegócio brasileiro.

O cultivo de cana-de-açúcar é reconhecido por apresentar concentração da produção em poucos países, contando com o Brasil e a Índia como principais produtores, tendo ambos respondido por aproximadamente 55\% da produção mundial em 2017 (Food and Agriculture Organization of the United Nations, 2019). Pelas particularidades geográficas e edafoclimáticas, no Brasil são possíveis duas safras no período de um ano, sendo uma na região Norte-Nordeste e outra no Centro-Sul, resultando na produção de açúcar e álcool todo ano para abastecimento tanto do mercado interno quanto do externo (União da Agroindústria Canavieira de São Paulo, 2019).

Ainda que o Brasil seja considerado grande produtor de cana-de-açúcar, verifica-se a existência de disparidades internas. Segundo dados da União da Agroindústria do Açúcar (União da Agroindústria Canavieira de São Paulo, 2019) e da Produção Agrícola Municipal (2019) para 2018, o Centro-Sul - área que agrupa as macrorregiões Sul, Sudeste e Centro-Oeste - responde por $90,74 \%$ de toda a área plantada de cana-de-açúcar, 90,78\% da área colhida e 92,91\% da produção no país. O estado de São Paulo foi responsável pelas maiores áreas plantada e colhida (5,5 milhões de hectares), quantidade produzida (433 milhões de toneladas) e rendimento médio da produção (77,9 toneladas por hectare) do Brasil, sendo sua produção responsável por $57,99 \%$ da produção nacional.

Em contraposição, podem-se examinar os dados referentes à região Norte-Nordeste (inclui as macrorregiões Norte e Nordeste) em 2018. As áreas plantada e colhida referem-se a 9,26\% e 9,22\%, respectivamente, e a quantidade produzida representa $7,09 \%$ do país. É notável a discrepância entre as regiões quando se abordam temas de produtividade e rendimento, apontando indícios da existência de diferenças regionais, seja pela diferença da dinâmica econômica, seja pela estrutura produtiva (Rosário et al., 2011; Produção Agrícola Municipal, 2019; União da Agroindústria Canavieira de São Paulo, 2019).

Tais disparidades estão relacionadas a fatores que envolvem competividade, adoção de tecnologias, inovação, entre outras motivações, e apesar de a agroindústria canavieira nordestina ser evidenciada por parcela significativa em sua economia regional, caracteriza-se como uma região com baixa produtividade e de atraso tecnológico. A sua continuidade deu-se principalmente pela articulação de usineiros e cultivadores de cana-de-açúcar no estado com mecanismos de subsídios, reservas de mercado etc. (Lima \& Melo, 1989).

Por outro lado, o Centro-Sul é qualificado como uma região mais produtiva e competitiva por sua dinâmica econômica e tecnológica. Confrontando aspectos de cada macrorregião (Centro-Sul e Norte-Nordeste), as diferenças são notáveis e evidenciam heterogeneidades produtivas, em que uma se define como mais atrasada e intensiva em mão de obra (Norte-Nordeste) e outra, mais moderna e intensiva em capital (Centro-Sul) (Ferreira Filho, 2013; Rissardi Júnior, 2015; Bastos, 2019). 
Pesquisas empíricas comprovam a disparidade e a segmentação salarial no mercado de trabalho brasileiro, as quais confirmam que desigualdades de salários são superiores em regiões mais dinâmicas e desenvolvidas relativamente às localidades mais atrasadas (Gomes \& Souza, 2018; Maia \& Souza, 2019; Mantovani et al., 2021). Portanto, seguindo a mesma linha de raciocínio, esta pesquisa pretende incluir ao rol científico informações comparativas entre as regiões Centro-Sul e Norte-Nordeste sobre as diferenças salariais para os trabalhadores ocupados no cultivo de cana-de-açúcar. Avanços metodológicos e a ampliação da coleta de dados da PNAD-C², principalmente em relação ao meio rural, permitem explorar ainda mais os elementos, bem como os esclarecer com mais robustez, cuja utilização ainda é uma lacuna na literatura acerca do tema.

Com isso, há possibilidade de conectar temas sociais e econômicos com procedimentos estatísticos detalhados para as macrorregiões selecionadas. Tal fato contribuirá com a elaboração ou aprimoramento de políticas públicas locais de desenvolvimento para amenizar diferenças das remunerações geradas pelo mercado de trabalho, assim como a inclusão dos trabalhadores do cultivo de cana-de-açúcar no mercado e não à sua margem.

Reconhecida a importância da cultura de cana-de-açúcar no país e uma gama considerável de pesquisas sobre tal assunto (Lima \& Melo, 1989; Balsadi, 2007; Estanislau et al., 2008; Orlandi et al., 2011; Rissardi Júnior, 2015; Martins et al., 2016; Pintor et al., 2015; Mazzuchetti \& Shikida, 2017; Wissmann \& Shikida, 2017; Feltre \& Perosa, 2020), também se faz necessário dar ênfase ao debate dos indivíduos que pertencem a esse mercado de trabalho. Balsadi (2007) afirmou que esse tipo de pesquisa permitirá avaliar a qualidade do emprego, já que esses empregados possuem extensa rotina de trabalho.

Com o baixo custo obtido nos produtos derivados da cana-de-açúcar, nota-se que a remuneração da mão de obra empregada nesse tipo de ocupação é muito baixa. Esse trabalho tem como objetivo identificar as desigualdades salariais dos trabalhadores inseridos na cultura de cana-de-açúcar nas macrorregiões produtoras Centro-Sul e Norte-Nordeste e mensurar suas causas para os hiatos salariais regionais com base nos microdados da PNAD-C para 2012 e 2019.

Além dessa introdução, esta pesquisa organiza-se em mais quatro seções. A segunda seção expõe uma concisa revisão de literatura teórica e estudos empíricos sobre o tema. A terceira seção reúne a metodologia selecionada, assim como a base de dados escolhida para análise da segmentação regional. Em seguida, a quarta seção descreve os resultados e a interpretação dos dados. Por fim, apresentam-se as conclusões.

\section{TEORIAS SOBRE A DIFERENÇA SALARIAL E EVIDÊNCIAS EMPÍRICAS DO MERCADO DE TRABALHO DA CANA-DE-AÇÚCAR}

As diferenças salariais estão demonstradas na teoria do diferencial compensatório de salários, teoria do capital humano, teoria da discriminação e na teoria da segmentação. A teoria do diferencial compensatório vista em Smith (1983) afirma que os empregados e os trabalhos são diferentes entre si quando se trata de suas qualificações, do bem-estar e das condições que os empregos oferecem. A teoria do capital humano está exposta em Mincer (1958), o qual centralizou sua teoria em apenas duas variáveis, experiência e qualificação, salientando ainda que existe uma correlação entre a educação do indivíduo e sua renda pessoal. A teoria da discriminação fundamenta que os trabalhadores são alocados de forma ineficiente no mercado

2 A PNAD-C propicia uma cobertura territorial mais abrangente do que a antiga PNAD, enquanto a PNAD "antiga" alcançou cobertura completa do território nacional, mediante a inserção dos estados de Rondônia, Acre, Amazonas, Roraima, Pará e Amapá. A PNAD-C é caracterizada pela representatividade amostral em relação à cobertura do meio rural desde sua implementação em 2011. 
de trabalho e auferem um rendimento menor que seu produto marginal, produzindo salários dessemelhantes e tratamentos diferenciados (Becker, 1962, 1971).

Em consequência às críticas realizadas sobre a teoria do capital humano, a teoria da segmentação, conhecida também como mercado dual, passou a ser mais discutida. A segmentação ocorre quando trabalhadores com a mesma produtividade auferem diferentes rendimentos em empregos distintos. A dualidade origina-se de uma falha do mercado, pois, com o efeito da segmentação em determinada economia, a alocação da força de trabalho não pode ser considerada eficiente. Assim, seria necessária a redistribuição desses trabalhadores de um setor para outro, resultando em aumento do produto nacional (Solimano, 1988).

A teoria da segmentação enuncia que o mercado de trabalho é fragmentado em dois segmentos, o mercado primário e o mercado secundário, os quais são diferenciados principalmente pelas características de estabilidade. O primeiro segmento está associado aos indivíduos com condições de trabalho privilegiadas; estão inseridos em postos de trabalho que se caracterizam pelo alto nível de qualificação, remuneração e produtividade; desfrutam de segurança e estabilidade de emprego; de oportunidades de promoções na carreira (Doeringer \& Piore, 1970; Reich et al., 1973; Vietorisz \& Harrison, 1973; Cacciamali de Souza, 1978; Lima, 1980).

Já o segundo mercado, qualificado como um segmento periférico, é constituído por empregos em situações de vulnerabilidade; baixos salários; alta rotatividade; péssimas condições de trabalho; baixa produtividade; compreendem profissões que não exigem ou demandam alta qualificação; promoções dentro das firmas são relativamente escassas; alto desemprego e estagnação tecnológica (Doeringer \& Piore, 1970; Reich et al., 1973; Cacciamali de Souza, 1978; Lima, 1980).

A teoria da segmentação constitui-se de diversos enfoques que se complementam para explicar a motivação da dualidade do mercado de trabalho. Para Doeringer \& Piore (1970), a segmentação é gerada pelo ajuste alocativo, ou seja, as características pessoais do trabalhador (cor da pele, gênero etc.) determinam a qual segmento o indivíduo será alocado. Vietorisz \& Harrison (1973) argumentam que o dualismo tecnológico intensificado pelo processo de concentração do capitalismo auxiliou a separação do mercado de trabalho. Por último, Reich et al. (1973) declaram que a presença de diferentes classes sociais, aliada ao sistema educacional, foi a fomentadora da dualidade do mercado.

Sendo assim, o salário de um indivíduo não é definido apenas por seu grau de instrução, como expõe a teoria do capital humano, mas também é influenciado pela região onde reside. 0 hiato salarial devido à segmentação regional se dá quando os indivíduos possuem os mesmos atributos, produtividades e níveis de qualificações. Contudo, são vistos de forma diferenciada pela perspectiva dos salários devido à localização da região de moradia. Constatações empíricas comprovam a presença de hiatos salariais entre os trabalhadores, como Menezes et al. (2005), Staduto \& Maldaner (2010), Botelho \& Vladimir (2011), Cirino \& Lima (2012), Gomes \& Souza (2018), Maia \& Souza (2019) e Mantovani et al. (2021). Os estudos mencionados confirmaram a diferença salarial entre os indivíduos ocupados em diferentes regiões e esse hiato é especificado pela ideia da segmentação regional.

O campo de pesquisa sobre a cana-de-açúcar é vasto; existem estudos sobre processo de criação de tecnologia (Shikida et al., 2000; Shikida \& Bacha, 2019), geração de empregos e produção do açúcar e álcool (Martins et al., 2016), comércio internacional do açúcar (Pintor et al., 2015; Mazzuchetti \& Shikida, 2017), impactos sociais e ambientais da agroindústria canavieira (Wissmann \& Shikida, 2017), governança no setor sucroalcooleiro (Feltre \& Perosa, 2020), entre outros. Especificamente ao mercado de trabalho da agroindústria canavieira, alguns trabalhos podem ser evidenciados, como Balsadi (2007), Moraes (2007a), Moraes (2007b), Junior \& Liboni 
(2008), Baccarin et al. (2008), Estanislau et al. (2008), Orlandi et al. (2011), Ferreira Filho (2013), Fernandes et al. (2013), Moraes et al. (2015), Xavier et al. (2017) e Bastos (2019).

Ao ressaltar referências da literatura verificadas sobre o mercado de trabalho do setor canavieiro, Moraes (2007a) identificou crescimento no número de empregados formais (52,9\%) envolvidos na produção de cana-de-açúcar, açúcar e álcool, estando $65 \%$ desses trabalhadores em 2005 na região Centro-Sul. Contudo, a autora verifica que o aumento do número de empregos formais foi menor para os incluídos no cultivo (16,2\%) quando se confrontam com os valores das usinas de açúcar (101,9\%) e destilarias de álcool $(88,4 \%)$.

Moraes (2007b) explorou os dados da Relação Anual de Informações Sociais (RAIS) e Pesquisa Nacional por Amostra de Domicílios (PNAD) para estudar os ambientes institucional e organizacional do mercado de trabalho do setor sucroalcooleiro do Brasil no período de 1992 a 2005. Encontrou resultados interessantes, como: 1) redução de $23 \%$ do número de empregados nos anos analisados; ii) aumento do nível de qualificação dos trabalhadores, embora este ainda permaneça muito baixo; iii) os rendimentos auferidos pelos empregados no setor do cultivo de cana-de-açúcar são menores quando comparados aos salários pagos pela indústria de álcool e do açúcar; iv) os rendimentos pagos à região produtora Centro-Sul são superiores aos do Norte-Nordeste.

O trabalho de Baccarin et al. (2008) identificou o crescimento do emprego canavieiro entre 2003 e 2006, sendo tal fato induzido pela expansão da área plantada e cultivada com cana-de-açúcar. Além do aumento do emprego, constataram queda do nível de salários dos canavieiros no período de 1995 a 2006. No entanto, a intensificação e a aceleração da mecanização da colheita, com a expansão da área de produção, resultarão na redução do número de empregados inseridos no cultivo de cana-de-açúcar.

Estanislau et al. (2008) observaram o trabalhador paranaense da agroindústria canavieira de 1995 a 2008. Por meio dos dados da RAIS, concluíram que nos setores que integram a agroindústria canavieira (cultivo de cana-de-açúcar, produção de açúcar e produção de álcool) houve aumento de $79 \%$ no número de empregados formais, assim como dos empregados que pertencem à faixa etária dos 40 aos 49 anos, a qual obteve mais aumento (254\%), indicando uma população de trabalhadores mais "velhos" nesse segmento produtivo. Além disso, houve um acréscimo na qualificação desses indivíduos e, ainda, maiores remunerações para aqueles com elevados níveis educacionais.

Ferreira Filho (2013) relatou que a renda e o nível médio de escolaridade dos trabalhadores na produção de cana-de-açúcar são realmente maiores do que na agricultura em geral no Brasil e esse comportamento está associado ao aumento crescente da produção nas regiões Sudeste e Centro-Oeste. Destacou que a produção no Centro-Sul se qualifica por ser mais intensiva em capital e ter mais produtividade, ao mesmo tempo que na região Nordeste a produtividade é menor e o cultivo é intensivo em mão de obra.

Por meio do método de shift-share, Fernandes et al. (2013) analisaram o desempenho do mercado de trabalho formal no setor sucroalcooleiro de 1995 a 2009. Para a realização da pesquisa, utilizaram os dados da RAIS e verificaram que a região Centro-Oeste gerou mais empregos no período selecionado, além do comportamento migratório dos postos de trabalho da região Nordeste em direção ao Sudeste e Centro-Oeste.

Com o objetivo de examinar os impactos socioeconômicos da indústria brasileira de cana-de-açúcar ${ }^{3}$ mediante as características da mão de obra, remuneração e condições de trabalho, Moraes et al. (2015) utilizaram dados da RAIS e PNAD para 2000 e 2012. Os resultados mostraram redução no número de trabalhadores formais para ambas as regiões produtoras:

3 Cultivo de cana, produção de açúcar e produção de etanol. 
Centro-Sul (- 7,1\%) e Norte-Nordeste (- 8,3\%). Evidenciaram ainda que o contexto familiar desempenha um papel relevante nas escolhas feitas pelos trabalhadores de segunda geração (filhos) em relação ao trabalho, impactando, assim, nos indicadores socioeconômicos dos setores analisados.

Xavier et al. (2017) analisaram as relações de trabalho no setor sucroalcooleiro da região Nordeste de 2006 a 2015. Afirmam que o segmento produtivo é caracterizado pela manutenção de baixos salários, alta rotatividade e precárias condições de trabalho no período analisado, fato evidenciado mesmo após aumento da produtividade a partir de 2013, o que pode resultar em mais exploração do trabalhador no cultivo de cana-de-açúcar. Bastos (2019) destaca que o sistema de produção da cana-de-açúcar no Nordeste é intensivo em mão de obra, com o uso de métodos pouco desenvolvidos e restritos. Apesar de uma melhora após a introdução tecnológica nesse setor, como o emprego da prática de fertilização, utilização de defensivos, substituição de variedades, nota-se grande atraso em relação às regiões mais desenvolvidas do país.

Diante disso, verifica-se que o Brasil é formado por regiões díspares e heterogêneas, em que algumas localidades são mais desenvolvidas, dinâmicas e produtivas, como o Centro-Sul, e outras regiões são mais atrasadas e menos competitivas, como o Norte-Nordeste. Teoricamente, a determinação dos salários dos trabalhadores deve ser baseada nos atributos pessoais, mas o mercado de trabalho pode estar gerando uma segmentação. Quando a diferença salarial está relacionada à localidade em que o empregado reside e não aos aspectos produtivos do empregado, pode ser denominada de segmentação regional.

Assim, esta pesquisa tem como foco identificar as desigualdades salariais dos trabalhadores inseridos na cultura de cana-de-açúcar nas macrorregiões produtoras Centro-Sul e Norte-Nordeste, tendo a região de residência do empregado como motivador e fonte das diferenças de rendimentos. Para determinar os hiatos salariais entre esses trabalhadores, aplicaram-se as regressões mincerianas e quantílicas, bem como a decomposição de Oaxaca (1973) e Blinder (1971) na média e por quantis, os quais estão expostos na próxima seção.

\section{METODOLOGIA}

\subsection{Base de dados}

Para a realização deste estudo, foram utilizados:

a. Os microdados da primeira visita da Pesquisa Nacional por Amostra de Domicílios Contínua (PNAD-C) (Instituto Brasileiro de Geografia e Estatística, 2012; 2018).

b. Indivíduos ocupados no mercado de trabalho.

c. Trabalhadores com $14^{4}$ anos ou mais de idade.

d. Indivíduos com rendimentos positivos de 2012 e 2019.

e. Trabalhadores estratificados de acordo com o local de residência ${ }^{5}$, ou seja, se possuem domicílio na macrorregião produtora Centro-Sul ou na região Norte-Nordeste.

A escolha do período justifica-se pelas diferentes realidades da economia brasileira, em que, em 2012, identificaram-se baixa taxa de desemprego (7,4\%) (Instituto Brasileiro de Geografia e Estatística, 2020; Instituto de Pesquisa Econômica Aplicada, 2020) e alta taxa de crescimento de

${ }^{4}$ No Brasil, a idade mínima permitida para qualquer trabalho é de 16 anos de idade. No entanto, pessoas com 14 anos podem exercer algumas funções no mercado de trabalho apoiadas pela Consolidação das Leis Trabalhistas como na condição de menor aprendiz (Brasil, 2000).

${ }^{5}$ Este trabalho considera a região de residência (macrorregião produtora) como método de estratificação dos trabalhadores e não o local de trabalho. 
atividade econômica, especialmente no setor agropecuário, o qual foi caracterizado com uma variação de 27,78\% no período (Instituto de Pesquisa Econômica Aplicada, 2020). Contrastando com 2012, o ano de 2019 ainda sem recuperação da recessão dos anos anteriores, o país obteve altas taxas de desemprego (11,93\%) (Instituto Brasileiro de Geografia e Estatística, 2020; Instituto de Pesquisa Econômica Aplicada, 2020) e baixo crescimento da economia, correspondendo a 0,27\% do PIB nacional (Instituto de Pesquisa Econômica Aplicada, 2020).

Assim, permaneceram para análise 424.014 observações para 2012 e 291.972 observações em 2019 de trabalhadores formais e informais, separados em dois grupos: indivíduos que residem na região Centro-Sul (67,84\% e 59,96\% em 2012 e 2019, respectivamente) e indivíduos que moram na região Norte-Nordeste (32,16\%, em 2012, e 40,04\%, em 2019) (Instituto Brasileiro de Geografia e Estatística, 2012; 2018).

De acordo com a Classificação Nacional de Atividades Econômicas Domiciliar 2.0 (CNAE 2.0), esta pesquisa selecionou o trabalhador ocupado na cultura de cana-de-açúcar (código 011056) como objeto, além das regiões Norte-Nordeste e Centro-Sul, onde a primeira contém os estados das regiões Norte e Nordeste e a segunda agrupa os estados das regiões Sul, Centro-Oeste e Sudeste. As variáveis utilizadas para caracterizar os trabalhadores e os métodos usados neste estudo estão expostas no Quadro 1, as quais estão fundamentadas pelas teorias da seção 2 e aplicações em pesquisas como Cunha (2008), Staduto \& Maldaner (2010), Cirino \& Lima (2012), Gomes \& Souza (2018) e Mantovani et al. (2021).

Quadro 1. Variáveis usadas para equações salariais, correção de viés de seleção amostral e decomposição de salários

\begin{tabular}{|c|c|c|}
\hline \multicolumn{3}{|r|}{ Variável dependente } \\
\hline Variável & Código & Descrição \\
\hline $\operatorname{Ln}(\mathrm{W})^{7}$ & v403312 & $\begin{array}{l}\text { Logaritmo natural da renda habitual ajustada pelas horas de } \\
\text { trabalho }\end{array}$ \\
\hline \multicolumn{3}{|r|}{ Variáveis independentes } \\
\hline ESC & vd3005 & Nível de escolaridade do trabalhador \\
\hline \multirow{2}{*}{ EXP } & v2009 & \multirow{2}{*}{$\begin{array}{l}\text { Experiência do trabalhador (Idade do indivíduo - } 5 \text { - idade que } \\
\text { com que começou a trabalhar) }\end{array}$} \\
\hline & vd3005 & \\
\hline \multirow{2}{*}{ EXP2 $^{2}$} & v2009 & \multirow{2}{*}{ Variável experiência elevada ao quadrado } \\
\hline & vd3005 & \\
\hline \multirow{2}{*}{$\mathrm{M}$} & \multirow{2}{*}{ v2007 } & $=1$, se for mulher, 0 , caso contrário \\
\hline & & (Homem - controle) \\
\hline \multirow{2}{*}{$\mathrm{BR}$} & \multirow{2}{*}{ v2010 } & = 1, se for branco, 0 , caso contrário \\
\hline & & (Não branco - controle) \\
\hline \multicolumn{3}{|c|}{$\begin{array}{l}\text { Fonte: elaborada pelos autores com base nos microdados da PNAD-C } 2012 \text { e } 2019 . \\
\text { 1) Salário e rendimento serão tratados como sinônimos. 2) Os rendimentos de } 2012 \text { foram inflacionados com base no } \\
\text { Índice Nacional de Preços ao Consumidor Amplo (IPCA), com o objetivo de comparar os termos monetários de } 2012 \\
\text { com os de } 2019 ; 3)^{*} \text { Variável utilizada exclusivamente para o procedimento de correção de viés de seleção amostral. }\end{array}$} \\
\hline
\end{tabular}

${ }^{6}$ Esta classe compreende trabalhadores no cultivo de cana-de-açúcar e produção de toletes de cana-de-açúcar, quando atividade complementar ao cultivo.

7 Nesta pesquisa, salário e rendimento serão tratados como sinônimos. 
Quadro 1. Continuação...

\begin{tabular}{|c|c|c|}
\hline \multicolumn{3}{|r|}{ Variável dependente } \\
\hline Variável & Código & Descrição \\
\hline \multirow{3}{*}{ REG } & \multirow{3}{*}{ UF } & $\begin{array}{l}\text { CS: }=1 \text {, se residir nas regiões Centro-Oeste, Sul e Sudeste, } 0 \text {, } \\
\text { caso contrário }\end{array}$ \\
\hline & & $\begin{array}{l}\mathrm{NN}:=1 \text {, se residir nas regiões Norte e Nordeste, } 0 \text {, caso } \\
\text { contrário }\end{array}$ \\
\hline & & (Centro-Sul - controle) \\
\hline \multirow{2}{*}{$\mathrm{F}$} & \multirow{2}{*}{ vd4009 } & $=1$, se trabalhar no setor formal, 0 , caso contrário \\
\hline & & (Informal - controle) \\
\hline \multirow{5}{*}{ TRI } & \multirow{5}{*}{ Trimestre } & TRI1: = 1, se for de janeiro a março, 0 , caso contrário \\
\hline & & TRI2: = 1 , se for de abril a junho, 0 , caso contrário \\
\hline & & TRI3: = 1, se for de julho a setembro, 0 , caso contrário \\
\hline & & TRI4: = 1, se for de outubro a dezembro, 0, caso contrário \\
\hline & & (primeiro trimestre (TRI1) - controle) \\
\hline \multirow[t]{2}{*}{ PEA* } & \multirow[t]{2}{*}{ vd4001 } & $\begin{array}{l}=1 \text {, se o indivíduo for uma pessoa economicamente ativa, } 0 \text {, } \\
\text { caso contrário. }\end{array}$ \\
\hline & & (PNEA - controle) \\
\hline \multirow{2}{*}{ URB } & \multirow{2}{*}{ v1022 } & $=1$, se o indivíduo residir na zona urbana, 0 , caso contrário \\
\hline & & (rural - controle) \\
\hline $\mathrm{CONJ}{ }^{*}$ & vd2002 & = 1 , se o indivíduo for considerado cônjuge, 0 , caso contrário \\
\hline CHEFE* & vd2002 & $\begin{array}{l}=1 \text {, se o indivíduo for considerado chefe da família, } 0 \text {, caso } \\
\text { contrário }\end{array}$ \\
\hline F0_5* & vd2002 & Quantidade de filhos que o indivíduo apresenta de 0 a 5 anos \\
\hline F6_13* & vd2002 & Quantidade de filhos que o indivíduo apresenta de 6 a 13 anos \\
\hline \multicolumn{3}{|c|}{$\begin{array}{l}\text { Fonte: elaborada pelos autores com base nos microdados da PNAD-C } 2012 \text { e } 2019 \text {. } \\
\text { 1) Salário e rendimento serão tratados como sinônimos. 2) Os rendimentos de } 2012 \text { foram inflacionados com base no } \\
\text { Índice Nacional de Preços ao Consumidor Amplo (IPCA), com o objetivo de comparar os termos monetários de } 2012 \\
\text { com os de 2019; 3)* Variável utilizada exclusivamente para o procedimento de correção de viés de seleção amostral. }\end{array}$} \\
\hline
\end{tabular}

\subsection{Equações de determinação de salários}

Inicialmente, efetuou-se o procedimento de correção de viés de seleção amostral proposto por Heckman (1979), por meio da estimação do modelo probit (Equação 1):

$P_{i}=\beta_{0}+\beta_{1} E S C_{i}+\beta_{2} E X P_{i}+\beta_{3} E X P_{i}^{2}+\beta_{4} B R_{i}+\beta_{5} U R B_{i}+\beta_{6} C O N J_{i}+\beta_{7} C H E F E_{i}+\beta_{8} F 0_{-} 5_{i}+\beta_{9} F \sigma_{-} 13_{i}+\beta_{10} M_{i}+\mu_{i}$

Posteriormente, os salários foram estimados por meio da equação log-lin desenvolvida por Mincer (1974), assim como por quantis - $10^{\circ}, 50^{\circ}$ e $90^{\circ}$ (Koenker \& Basset, 1978; Scicchitano, 2012) para os trabalhadores empregados no cultivo de cana-de-açúcar, nas macrorregiões Centro-Sul e Norte-Nordeste, de 2012 e 2019.

A equação minceriana semilogarítmica é utilizada em trabalhos que têm por objetivo mensurar o retorno dos salários, dadas as características produtivas e não produtivas dos indivíduos (Mincer, 1974). As regressões quantílicas permitem a análise de trabalhadores com baixos, médios e altos rendimentos. Além de fornecer uma comparação com a média (regressão minceriana), as regressões quantílicas originam uma análise mais completa entre 
as variáveis, avaliando diferentes pontos da distribuição da variável dependente (Koenker \& Basset, 1978; Scicchitano, 2012). As regressões mincerianas (Equação 2) e quantílicas (Equaação 3) podem ser escritas como:

$\ln \left(W_{i}\right)=x_{i}^{\prime} \beta_{\theta}+\varepsilon_{\theta i}$

$\operatorname{Quant}_{\theta}\left(\left(\ln \left(W_{i}\right) / x_{i}^{\prime}\right)=x_{i}^{\prime} \beta_{\theta}\right.$

$\ln \left(W_{i}\right)$ representa o logaritmo natural da renda ajustada por horas de trabalho, representa um vetor de características pessoais do indivíduo e dos segmentos do mercado de trabalho (variáveis explicativas) e, por fim, $\varepsilon_{\theta i}$ é o termo de erro. O termo $\operatorname{Quant}_{\theta}\left(\ln \left(W_{i}\right) / x_{i}^{\prime}\right)=x_{i}^{\prime} \beta_{\theta}$ corresponde ao quantil condicional de $\ln \left(W_{i}\right)$ (variável aleatória real $(i=1, \ldots, \mathrm{n})$, dado $x_{i}^{\prime}$ (vetor $K x 1$ de variáveis explicativas), e $\beta_{\theta}$ é um vetor de parâmetros.

Reescrevendo as Equações 2 e 3 - análise para a média e para quantis respectivamente - e empregando as variáveis dependente e independentes (Quadro 1), após a correção proposta por Heckman (1979), tem-se:

$$
\begin{aligned}
& \ln \left(W_{i}\right)=\beta_{0}+\beta_{1} E S C_{i}+\beta_{2} E X P_{i}+\beta_{3} E X P_{i}^{2}+\beta_{4} M_{i}+\beta_{5} B R_{i}+\beta_{6} F_{i}+\beta_{7} U R B_{i}+\beta_{8} C S_{i}+\beta_{9} \lambda+\mu_{i} \\
& \ln \left(W_{\theta i}\right)=\beta_{0}+\beta_{1} E S C_{\theta i}+\beta_{2} E X P_{\theta i}+\beta_{3} E X P_{\theta i}^{2}+\beta_{4} M_{\theta i}+\beta_{5} B R_{\theta i}+\beta_{6} F_{\theta i}+\beta_{7} U R B_{\theta i}+\beta_{8} C S_{\theta i}+\beta_{9} \lambda+\mu_{\theta i}
\end{aligned}
$$

Dessa forma, estimaram-se os parâmetros na média (Equação 4) e para diferentes pontos da distribuição dos rendimentos, sendo eles: $10^{\circ}, 50^{\circ}$ e $90^{\circ}$ (Equação 5), identificando os trabalhadores com baixos rendimentos, na mediana, e aqueles com altas rendas.

\subsection{Decomposição de salários}

Após a estimação das regressões de determinação de salários, efetuou-se a decomposição de Oaxaca (1973) e Blinder (1971) (Equação 6), bem como a decomposição salarial ao longo da

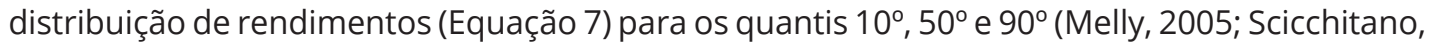
2012). Ambos os métodos permitem a divisão da equação de determinação de salário do indivíduo em duas partes: a primeira é composta da parte explicada pelas características pessoais; a segunda refere-se à parte não explicada, originada pelas proxies da discriminação, quando se estudam diferenças de gênero ou cor, ou proxy da segmentação regional, na análise das diferenças entre as regiões.

$$
\begin{aligned}
& \ln \left(W_{A}\right)-\ln \left(W_{B}\right)=\left(x_{A}-x_{B}\right) \beta_{A}+\left(\beta_{A}-\beta_{B}\right) x_{B} \\
& \text { Quant }_{\theta}\left[\ln \left(W_{A}\right)\right]-\text { Quant }_{\theta}\left[\ln \left(W_{B}\right)\right]= \\
& \left(x_{A, \theta}-x_{B, \theta}\right) \beta_{A, \theta}+\left(\beta_{A, \theta}-\beta_{B, \theta}\right) x_{B, \theta}
\end{aligned}
$$

Em que:

i) Subscrito A: Representa o grupo em vantagem (trabalhadores da região Centro-Sul);

ii) Subscrito B: Equivale ao grupo em desvantagem (trabalhadores da região Norte-Nordeste); 
iii) $\left(x_{A}-x_{B}\right) \beta_{A}\left(x_{A, \theta}-x_{B, \theta}\right) \beta_{A, \theta}$ : Constitui a diferença dos retornos salariais que os trabalhadores em diferentes regiões recebem por suas características no mercado de trabalho, isto é, a distribuição contrafactual (efeito explicado);

iv) $\left(\beta_{A}-\beta_{B}\right) x_{B}\left(\beta_{A, \theta}-\beta_{B, \theta}\right) x_{B, \theta}$ : Corresponde ao efeito das desigualdades nas características do mercado de trabalho entre indivíduos empregados nas macrorregiões produtoras Centro-Sul e Norte-Nordeste. Trata-se de uma proxy para o efeito da segmentação regional.

\section{DECOMPOSIÇÃO DOS SALÁRIOS E SEGMENTAÇÃO REGIONAL}

\subsection{Características dos trabalhadores de cana-de-açúcar segundo as regiões selecionadas}

Os perfis dos trabalhadores ocupados na cultura de cana-de-açúcar para as regiões Centro-Sul e Norte-Nordeste de 2012 e 2019 encontram-se na Tabela 1. Para a região Centro-Sul, os ocupados na cultura de cana-de-açúcar possuem rendimento médio de $\mathrm{R} \$ 1.887 .84$ por mês e $\mathrm{R} \$$ 9,22 por hora, em 2012, e R\$2.242,16 mensal e $\mathrm{R} \$ 12,21$ por hora, em 2019. Em 2012, esses empregados trabalhavam 49 horas por semana, enquanto, em 2019, passaram a trabalhar 44 horas semanalmente. Tais resultados evidenciam que a remuneração obteve acréscimo no período por um aumento do salário-hora médio e não em função da carga horária trabalhada.

Tabela 1. Características dos trabalhadores ocupados no cultivo de cana-de-açúcar nas regiões Centro-Sul e Norte-Nordeste - 2012 e 2019

\begin{tabular}{|c|c|c|c|c|}
\hline \multirow{2}{*}{ Variáveis } & \multicolumn{2}{|c|}{2012} & \multicolumn{2}{|c|}{2019} \\
\hline & C-S & $\mathbf{N}-\mathbf{N}$ & C-S & $\mathbf{N}-\mathbf{N}$ \\
\hline Horas de trabalho semanalmente (média) & 49,04 & 44,45 & 44,06 & 41,94 \\
\hline Desvio padrão & 10,66 & 12,54 & 8,21 & 10,29 \\
\hline Mediana & 48,00 & 45,00 & 44,00 & 44,00 \\
\hline Experiência (média) & 23,25 & 25,64 & 28,01 & 28,47 \\
\hline Desvio padrão & 13,19 & 14,48 & 14,79 & 14,61 \\
\hline Mediana & 22,00 & 23,00 & 27,00 & 27,00 \\
\hline Escolaridade (média) & 7,87 & 5,06 & 8,15 & 5,75 \\
\hline Desvio padrão & 3,71 & 3,97 & 4,09 & 4,12 \\
\hline Mediana & 8,00 & 5,00 & 9,00 & 5,00 \\
\hline Salário-mês (média) & $1.887,84$ & $1.080,78$ & $2.242,16$ & $1.001,42$ \\
\hline Desvio padrão & $1.615,07$ & 842,09 & $2.685,55$ & 546,45 \\
\hline Mediana & $1.545,30$ & 961,18 & $1.800,00$ & 998,00 \\
\hline Salário-hora (média) & 9,22 & 5,97 & 12,21 & 5,63 \\
\hline Desvio padrão & 9,91 & 7,03 & 17,76 & 3,67 \\
\hline Mediana & 7,42 & 4,81 & 8,66 & 5,24 \\
\hline Idade (média) & 36,12 & 35,70 & 41,16 & 39,22 \\
\hline Desvio padrão & 11,54 & 12,60 & 12,82 & 12,07 \\
\hline Mediana & 35,00 & 33,00 & 40,00 & 38,00 \\
\hline Mulher (\%) & $15,04 \%$ & $5,72 \%$ & $10,89 \%$ & $4,69 \%$ \\
\hline Desvio padrão & 0,36 & 0,23 & 0,31 & 0,21 \\
\hline Mediana & 0,00 & 0,00 & 0,00 & 0,00 \\
\hline Homem (\%) & $84,96 \%$ & $94,28 \%$ & $89,11 \%$ & $95,31 \%$ \\
\hline Desvio padrão & 0,36 & 0,23 & 0,31 & 0,21 \\
\hline Mediana & 1,00 & 1,00 & 1,00 & 1,00 \\
\hline
\end{tabular}

Fonte: elaborada pelos autores com base nos microdados da PNAD-C 2012 e 2019. C-S: Centro-Sul; N-N: Norte-Nordeste. 
Tabela 1. Continuação...

\begin{tabular}{|c|c|c|c|c|}
\hline \multirow{2}{*}{ Variáveis } & \multicolumn{2}{|c|}{2012} & \multicolumn{2}{|c|}{2019} \\
\hline & C-S & $\mathbf{N}-\mathbf{N}$ & C-S & $\mathbf{N}-\mathbf{N}$ \\
\hline Branco (\%) & $46,69 \%$ & $20,76 \%$ & $42,97 \%$ & $17,54 \%$ \\
\hline Desvio padrão & 0,50 & 0,41 & 0,50 & 0,38 \\
\hline Mediana & 0,00 & 0,00 & 0,00 & 0,00 \\
\hline Não branco (\%) & $53,31 \%$ & $79,24 \%$ & $57,03 \%$ & $82,46 \%$ \\
\hline Desvio padrão & 0,50 & 0,41 & 0,50 & 0,38 \\
\hline Mediana & 1,00 & 1,00 & 1,00 & 1,00 \\
\hline Chefe de família (\%) & $60,25 \%$ & $59,16 \%$ & $60,71 \%$ & $54,99 \%$ \\
\hline Desvio padrão & 0,49 & 0,49 & 0,49 & 0,50 \\
\hline Mediana & 1,00 & 1,00 & 1,00 & 1,00 \\
\hline Cônjuge ou companheiro (\%) & $12,23 \%$ & $13,92 \%$ & $22,85 \%$ & $29,18 \%$ \\
\hline Desvio padrão & 0,33 & 0,35 & 0,42 & 0,45 \\
\hline Mediana & 0,00 & 0,00 & 0,00 & 0,00 \\
\hline Urbana (\%) & $80,62 \%$ & $44,35 \%$ & $80,18 \%$ & $39,47 \%$ \\
\hline Desvio padrão & 0,40 & 0,50 & 0,40 & 0,49 \\
\hline Mediana & 1,00 & 1,00 & 1,00 & 0,00 \\
\hline Rural (\%) & $19,38 \%$ & $55,65 \%$ & $19,82 \%$ & $60,53 \%$ \\
\hline Desvio padrão & 0,40 & 0,50 & 0,40 & 0,49 \\
\hline Mediana & 0,00 & 1,00 & 0,00 & 1,00 \\
\hline Formal (\%) & $86,28 \%$ & $77,00 \%$ & $82,06 \%$ & $64,15 \%$ \\
\hline Desvio padrão & 0,34 & 0,42 & 0,38 & 0,48 \\
\hline Mediana & 1,00 & 1,00 & 1,00 & 1,00 \\
\hline Informal (\%) & $13,72 \%$ & $23,00 \%$ & $17,94 \%$ & $35,85 \%$ \\
\hline Desvio padrão & 0,34 & 0,42 & 0,38 & 0,48 \\
\hline Mediana & 0,00 & 0,00 & 0,00 & 0,00 \\
\hline Número de trabalhadores & 287.656 & 136.358 & 175.059 & 116.913 \\
\hline
\end{tabular}

Fonte: elaborada pelos autores com base nos microdados da PNAD-C 2012 e 2019. C-S: Centro-Sul; N-N: Norte-Nordeste.

Caracterizam-se também pela baixa qualificação, detêm 23 e 28 anos de experiência em 2012 e 2019, respectivamente, e definem-se também por ter idade média de 36 anos, em 2012, e 41 anos, em 2019. Os trabalhadores dessa região são majoritariamente não brancos, homens, chefes de família, residentes da área urbana e pertencem ao mercado de trabalho formal (Tabela 1).

Em relação aos trabalhadores que residem na região Norte-Nordeste, em termos monetários auferem $R \$ 1.080$,78 e $R \$ 5,97$ por mês e hora, respectivamente, em 2012, $R \$ 1.001,42$ mensal e $R \$ 7,63$ por hora, em 2019, apresentando rendimentos inferiores para os dois anos quando comparados aos trabalhadores da macrorregião Centro-Sul. Os empregados dessa região também vivenciaram redução na jornada de trabalho, com diminuições nas remunerações médias por mês e hora (Tabela 1).

Similarmente a outra localidade, os trabalhadores do Norte-Nordeste possuem baixo nível educacional, embora a quantidade de anos de estudo seja superior no Centro-Sul. Apresentam experiência levemente superior ao grupo de trabalhadores que moram na outra região (25 anos, em média, em 2012 e 28 anos, em 2019) e exibem 35 anos e 39 anos, em média, para 2012 e 2019. A maioria desses empregados é não branca - proporções maiores do que as exibidos no Centro-Sul -, homem, chefe de família, localiza-se na área rural e está inserida no setor formal do mercado de trabalho, embora se note alta taxa de informalidade. 
As disparidades tornam-se evidentes quando se analisam os rendimentos. Por exemplo, um trabalhador do cultivo de cana-de-açúcar residente na região Centro-Sul aufere $R \$ 12,21$ por hora em 2019, enquanto um empregado da mesma produção no Norte-Nordeste recebe R\$ 5,63 em 2019 (Tabela 1). Alguns fatores desempenham um poder de explicação para essa heterogeneidade regional, como custos de vidas díspares (Menezes \& Azzoni, 2006; Almeida \& Azzoni, 2016; Departamento Intersindical de Estatística e Estudos Socioeconômicos, 2021); movimento de migração dos indivíduos para realizar o trabalho no Centro-Sul devido à sazonalidade da cultura (Fernandes et al., 2013; Feltre \& Perosa, 2020); padrão tecnológico distinto entre as duas regiões, bem como suas diferentes dinâmicas e estruturas produtivas (Rosário et al., 2011). Além dos atributos pessoas e produtivos dos trabalhadores exibidos na Tabela 1, características regionais também exercem grande influência sobre a produtividade e remuneração do indivíduo inserido no cultivo de cana-de-açúcar.

Tais dados revelam indícios da segmentação regional devido ao local que o trabalhador reside, a qual pode estar relacionada diretamente aos diferentes perfis tecnológicos e às estruturas produtivas das macrorregiões produtoras, sendo uma mais intensiva em capital e com mais produtividade (Centro-Sul) e outra mais intensiva em mão de obra e atrasada em relação às regiões mais desenvolvidas (Rosário et al., 2011; Ferreira Filho, 2013; Bastos, 2019). Outro fator está associado aos movimentos de migração de trabalhadores e de expansão do setor no Centro-Sul (Ferreira Filho, 2013; Bastos, 2019; Feltre \& Perosa, 2020), ocasionando influências na produtividade e nos rendimentos dos trabalhadores no cultivo.

Os dados expostos na Tabela 1 apresentam certas simetrias com pesquisas empíricas sobre o tema, como: i) mesmo que o número de anos de estudo dos empregados no cultivo de cana-de-açúcar tenha evoluído, nota-se que ainda é baixo (Moraes, 2007a, 2007b; Junior \& Liboni, 2008; Hoffmann \& Oliveira, 2008; Estanislau et al., 2008; Liboni, 2009; Orlandi et al., 2011; Moraes et al., 2015; Xavier et al., 2017); ii) maior parcela desses trabalhadores concentra-se na faixa etária de 30 a 39 anos (Moraes, 2007b; Estanislau et al., 2008; Orlandi et al., 2011; Xavier et al., 2017); iii) homens são a maioria dos trabalhadores no cultivo (Estanislau et al., 2008; Xavier et al., 2017); iv) a maior parte tem carteira assinada, isto é, são trabalhadores formais (Moraes, 2007a, 2007b; Junior \& Liboni, 2008; Hoffmann \& Oliveira, 2008; Liboni, 2009; Santos Júnior, 2012; Fernandes et al., 2013); v) a remuneração da macrorregião Norte-Nordeste é inferior quando comparada à da região produtora Centro-Sul (Moraes, 2007a, 2007b; Junior \& Liboni, 2008; Hoffmann \& Oliveira, 2008; Liboni, 2009; Moraes et al., 2015).

Outro dado a ser ressaltado trata-se do número de trabalhadores ocupados no cultivo de cana-de-açúcar. Houve diminuição de 39\% e 16\% dos trabalhadores nas regiões Centro-Sul e Norte-Nordeste e resultados semelhantes podem ser vistos em Balsadi (2007), Estanislau et al. (2008), Abreu et al. (2008) e Xavier et al. (2017). A redução da força de trabalho nessa ocupação está associada a diversos fatores, como dinâmica econômica e produtiva das regiões (Rosário et al., 2011), técnicas poupadoras de mão de obra (Orlandi et al., 2011; Santos Júnior, 2012; Bastos, 2019), intensificação e modernização da mecanização da lavoura canavieira (Moraes, 2007b; Baccarin et al., 2008; Abreu et al., 2008; Liboni, 2009; Orlandi et al., 2011; Santos Júnior, 2012; Ferreira Filho, 2013; Moraes et al., 2015); proibição da queima da cana-de-açúcar como método de despalha (Moraes, 2007b; Liboni, 2009); aplicação da legislação trabalhista com a imposição do teto mínimo (salário mínimo) para o trabalhador formal (Moraes, 2007b; Orlandi et al., 2011). 


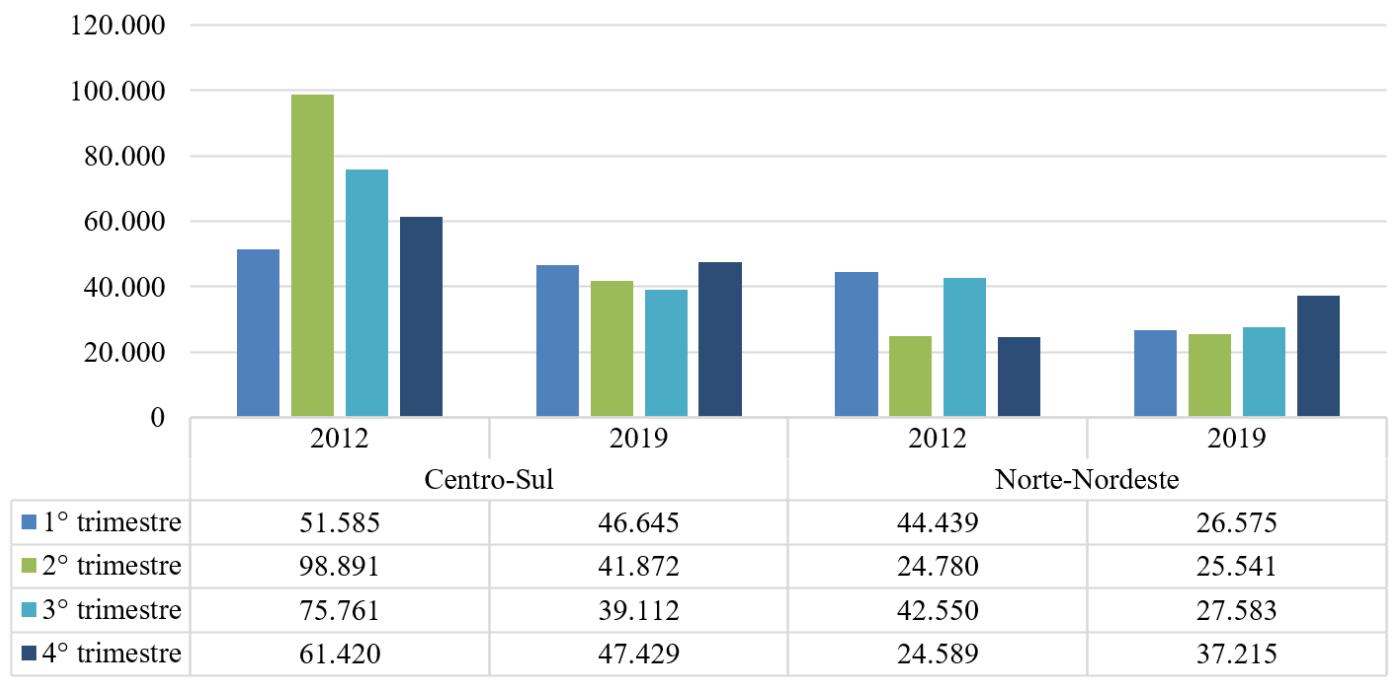

Figura 1. Número de trabalhadores ocupados no cultivo de cana-de-açúcar nas regiões Centro-Sul e Norte-Nordeste - 2012 e 2019.

Fonte: Elaborada pelos autores com base nos microdados da PNAD-C 2012 e 2019.

Além do perfil produtivo do trabalhador, a sazonalidade do emprego associada à cultura de cana-de-açúcar deve ser destacada (Figura 1). Dados de 2012 evidenciam que o Centro-Sul apresentou aumento do número de trabalhadores no segundo trimestre, ao passo que no Norte-Nordeste a elevação ocorreu no terceiro trimestre. Essas informações correspondem ao período de safra do cultivo, em que o Centro-Sul tem início em abril e se encerra em novembro, e o Norte-Nordeste começa em novembro e tem término em abril. Ademais, a dinâmica da economia brasileira teve impacto direto na quantidade dos trabalhadores. Enquanto o ano de 2012 qualificou-se pela baixa taxa de desemprego e alta taxa de crescimento de atividade econômica, principalmente no setor agropecuário, o ano de 2019, sem recuperação total da recessão dos anos anteriores, foi marcado por altas taxas de desemprego e baixo crescimento econômico (Instituto Brasileiro de Geografia e Estatística, 2020; Instituto de Pesquisa Econômica Aplicada, 2020), contribuindo para a redução do montante de trabalhadores ocupados.

Assim como a dinâmica econômica, outros fatores podem influenciar os dados expostos pela Figura 1, como diferentes custos de vida (Menezes \& Azzoni, 2006; Almeida \& Azzoni, 2016; Departamento Intersindical de Estatística e Estudos Socioeconômicos, 2021), distintos perfis tecnológicos e estruturas produtivas entre as regiões (Moraes, 2007b; Baccarin et al., 2008; Abreu et al., 2008; Liboni, 2009; Orlandi et al., 2011; Santos Júnior, 2012; Ferreira Filho, 2013; Moraes et al., 2015), da mesma maneira que a circulação/migração da população ocupada no cultivo (Fernandes et al., 2013; Feltre \& Perosa, 2020). A condição da migração pode ser resultante da sazonalidade da cultura (Fernandes et al., 2013), existência de duas safras por ano e de condições insuficientes que garantam a sobrevivência e a permanência do trabalhador em sua região de origem (Santos Júnior, 2012). 
Tabela 2. Quantidade, participação (\%) e rendimento-hora médio $(R \$)$ dos trabalhadores ocupados no cultivo de cana-de-açúcar nas regiões Centro-Sul e Norte-Nordeste, segundo ocupações - 2012 e 2019

\begin{tabular}{|c|c|c|c|c|c|c|}
\hline \multicolumn{7}{|c|}{ Centro-Sul } \\
\hline \multirow{2}{*}{ Ocupações } & \multicolumn{3}{|c|}{2012} & \multicolumn{3}{|c|}{2019} \\
\hline & Quant. & $\%$ & $\mathbf{R} \$$ & Quant. & $\%$ & R\$ \\
\hline $\begin{array}{c}\text { Trabalhadores elementares da } \\
\text { agricultura }\end{array}$ & 99.970 & 34,75 & 6,19 & 32.533 & 18,58 & 7,95 \\
\hline $\begin{array}{c}\text { Operadores de máquinas agrícolas } \\
\text { móveis }\end{array}$ & 61.228 & 21,29 & 9,28 & 46.450 & 26,53 & 9,68 \\
\hline $\begin{array}{c}\text { Agricultores e trabalhadores qual. } \\
\text { ativ. agr. }\end{array}$ & 51.341 & 17,85 & 10,33 & 30.782 & 17,58 & 13,35 \\
\hline Outros & 75.117 & 26,11 & - & 65.294 & 37,31 & - \\
\hline \multicolumn{7}{|c|}{ Norte-Nordeste } \\
\hline \multirow{2}{*}{ Ocupações } & \multicolumn{3}{|c|}{2012} & \multicolumn{3}{|c|}{2019} \\
\hline & Quant. & $\%$ & R\$ & Quant. & $\%$ & R\$ \\
\hline $\begin{array}{l}\text { Trabalhadores elementares da } \\
\text { agricultura }\end{array}$ & 78.281 & 57,41 & 5,11 & 62.340 & 53,32 & 5,35 \\
\hline $\begin{array}{c}\text { Operadores de máquinas agrícolas } \\
\text { móveis }\end{array}$ & 8.710 & 27,74 & 7,19 & 11.109 & 22,80 & 5,07 \\
\hline $\begin{array}{c}\text { Agricultores e trabalhadores qual. } \\
\text { ativ. agr. }\end{array}$ & 37.825 & 6,39 & 5,69 & 26.652 & 9,50 & 7,86 \\
\hline Outros & 11.542 & 8,46 & - & 16.812 & 14,38 & - \\
\hline
\end{tabular}

Fonte: elaborada pelos autores com base nos microdados da PNAD-C 2012 e 2019.

$\mathrm{R} \$$ : rendimento-hora médio.

Para ambos os anos e regiões, as ocupações de operadores de máquinas agrícolas, trabalhadores elementares da agricultura e agricultores e trabalhadores qualificados em atividades agrícolas empregam a maior parte dos trabalhadores inseridos no cultivo de cana-de-açúcar, correspondendo a 74\% e 85\%, em 2012, e 63\% e 86\%, em 2019, para o Centro-Sul e Norte-Nordeste, respectivamente (Tabela 2). Ocupações que envolvem agricultura prevaleceram com as maiores participações, mesmo quando o setor não tinha se recuperado totalmente da profunda crise econômica no Brasil iniciada em 2014. A produção agrícola teve nesse período um importante papel social e econômico na superação da crise, o que refletiu especialmente no aumento do salário-hora dos trabalhadores no Centro-Sul.

A cultura canavieira qualifica-se pela importância social e econômica para o Brasil. Economicamente, está relacionada à mecanização e à modernização da produção, enquanto o eixo social releva redução da mão de obra e altas taxas de desemprego (Abreu et al., 2008). Com um padrão tecnológico mais alto, dois fatores podem ser observados: positivamente, tem-se maior demanda de trabalhadores qualificados, enquanto, negativamente, verifica-se que a atividade está se deslocando no Nordeste do país e expandindo-se nas regiões mais desenvolvidas e dinâmicas (Ferreira Filho, 2013; Feltre \& Perosa, 2020).

A tecnologia da produção de cana-de-açúcar demonstra heterogeneidade no Brasil, em que o cultivo é mais intensivo em mão de obra em regiões mais tradicionais e atrasadas (Norte-Nordeste) e a produção é mais produtiva e intensiva em capital em locais mais ricos e dinâmicos (Centro-Sul) (Ferreira Filho, 2013). Diante dessa convivência de diferentes realidades internamente diferenciadas verificada empiricamente e por meio dos dados das Tabelas 1 e 2 e da Figura 1, notam-se indícios da presença da segmentação regional entre os empregados no cultivo de cana-de-açúcar. Para confirmar essa hipótese, foram estimadas equações salariais e efetuou-se a decomposição de salários, as quais serão exibidas nas próximas seções. 


\subsection{Determinação dos salários dos trabalhadores no cultivo de cana-de-açúcar}

As equações de determinações de salários estimadas para os trabalhadores no cultivo de cana-de-açúcar corrigidas pelo viés de seleção amostral (Tabela 3) mostram fatores que influenciam os salários dos trabalhadores ocupados segundo as macrorregiões produtoras em que residem. Os valores dos coeficientes representam o ganho percentual sobre o salário-hora que um trabalhador recebe ao acrescentar uma unidade do aspecto produtivo a ser analisado (para variáveis contínuas, como educação e experiência) ou por pertencer a uma classe (para variáveis categóricas, como cor, gênero ou setor).

Os resultados mostram que a escolaridade e a experiência contribuem para um maior salário, mantendo as outras variáveis constantes, confirmando os pressupostos da Teoria do Capital Humano (Mincer, 1958; Schultz, 1964; Lima, 1980) com efeitos maiores para o quantil $90^{\circ}$ quando comparados aos quantis inferiores da distribuição salarial. A variável "Experiência2" apresentou sinal negativo para as regressões minceriana e quantílicas, o que é esperado pela teoria, pois a experiência possui retornos marginais decrescentes (Tabela 3).

As mulheres apresentam perdas salariais para todas as regressões e em ambos os anos, sendo maiores para os quantis mais altos e no ano de 2019. Esses dados indicam que a remuneração masculina é mais elevada que a feminina, confirmando a desvalorização da mulher reconhecida em diversos estudos sobre o gênero (Estanislau et al., 2008; Gomes \& Souza, 2018; Maia \& Souza, 2019; Mantovani et al., 2021). A variável dummy que se refere à cor da pele do trabalhador exibe comportamento dessemelhante ao gênero (Maia \& Souza, 2019). Ser branco resulta em ganhos salariais, os quais são superiores para os trabalhadores com maiores salários (quantis $50^{\circ}$ e $90^{\circ}$, em 2019), o que evidencia diferença salarial devido à cor (Tabela 3).

Estar inserido no mercado de trabalho formal expõe ganhos tanto na regressão na média quanto para as quantílicas, bem como para os dois anos de análise. Isto reflete a vantagem de trabalhar formalmente quando comparado com os empregados ocupados no setor informal. Esse atributo apresenta comportamento diferenciado quando relacionado com as variáveis já mencionadas (gênero, cor da pele, escolaridade e experiência), pois os retornos positivos são maiores para aqueles com baixos rendimentos e menores para os que possuem altos salários (Tabela 3).

As variáveis referentes aos trimestres indicam que tanto a sazonalidade do cultivo quanto a dinâmica econômica do país influenciam os rendimentos dos trabalhadores. Em um período marcado por baixo desemprego e alta dinâmica da agropecuária (2012), indivíduos que trabalharam entre julho e dezembro tiveram ganhos salariais quando comparados com aqueles que trabalharam no primeiro trimestre (Tabela 3), comportamento associado ao período de safra, especialmente na região Centro-Sul. Além disso, em 2012, os prêmios salariais foram maiores para indivíduos com baixos rendimentos (quantil $10^{\circ}$ ), enquanto 2019 não forneceu nenhum dado estatisticamente significativo, o que pode estar relacionado com o comportamento da economia brasileira, a qual não obteve recuperação total das recessões anteriores. 
Tabela 3. Determinantes salariais dos trabalhadores ocupados no cultivo de cana-de-açúcar - 2012 e 2019

\begin{tabular}{|c|c|c|c|c|c|c|c|c|}
\hline \multirow{2}{*}{ Variáveis } & \multicolumn{4}{|c|}{2012} & \multicolumn{4}{|c|}{2019} \\
\hline & MQO & Q10 & Q50 & Q90 & MQO & Q10 & Q50 & Q90 \\
\hline Escolaridade & $\begin{array}{c}0,0477 \\
*\end{array}$ & 0,0164 & $\begin{array}{c}0,0299 \\
*\end{array}$ & $\begin{array}{c}0,0951 \\
*\end{array}$ & $\begin{array}{c}0,0746 \\
*\end{array}$ & $\begin{array}{c}0,0358 \\
* *\end{array}$ & $\begin{array}{c}0,0383 \\
*\end{array}$ & $\begin{array}{c}0,0924 \\
*\end{array}$ \\
\hline Experiência & $\begin{array}{c}0,0211 \\
* \star *\end{array}$ & 0,0204 & 0,0109 & $\begin{array}{c}0,0380 \\
* * *\end{array}$ & $\begin{array}{c}0,0317 \\
* *\end{array}$ & 0,0090 & 0,0082 & $\begin{array}{c}0,0544 \\
* *\end{array}$ \\
\hline Experiência² & $-0,0002$ & $\begin{array}{c}-0,0004 \\
\star \star \star\end{array}$ & $-0,0001$ & $-0,0004$ & $-0,0004$ & $-0,0001$ & $-0,0001$ & $\begin{array}{c}-0,0008 \\
\star \star \star\end{array}$ \\
\hline Mulher & $\begin{array}{c}-0,2463 \\
*\end{array}$ & $-0,1477$ & $\begin{array}{c}-0,2020 \\
*\end{array}$ & $-0,2708$ & $\begin{array}{c}-0,3133 \\
*\end{array}$ & $-0,1203$ & $-0,1177$ & $\begin{array}{c}-0,4997 \\
*\end{array}$ \\
\hline Branco & 0,0731 & $-0,0042$ & 0,0357 & 0,1325 & $\begin{array}{l}0,1703 \\
*\end{array}$ & 0,0379 & $\begin{array}{c}0,1010 \\
\star \star \star\end{array}$ & $\begin{array}{c}0,1658 \\
\star *\end{array}$ \\
\hline Formal & $\begin{array}{c}0,2594 \\
*\end{array}$ & $\begin{array}{c}0,8283 \\
*\end{array}$ & $\begin{array}{c}0,2158 \\
*\end{array}$ & $-0,0155$ & $\begin{array}{c}0,5485 \\
*\end{array}$ & $\begin{array}{c}1,2489 \\
*\end{array}$ & $\begin{array}{c}0,4481 \\
*\end{array}$ & $\begin{array}{c}0,2356 \\
*\end{array}$ \\
\hline Urbano & 0,0113 & 0,0288 & 0,0100 & 0,0502 & 0,0536 & $-0,0683$ & 0,0218 & $-0,0280$ \\
\hline Trimestre 2 & $\begin{array}{c}-0,0626 \\
\star \star\end{array}$ & 0,1110 & 0,0545 & 0,0976 & $-0,0450$ & $-0,0015$ & 0,0066 & 0,0875 \\
\hline Trimestre 3 & $\begin{array}{c}0,1125 \\
* *\end{array}$ & $\begin{array}{c}0,2326 \\
*\end{array}$ & $\begin{array}{c}0,1385 \\
*\end{array}$ & $\begin{array}{c}0,1974 \\
*\end{array}$ & $-0,0171$ & 0,0588 & 0,0220 & 0,1350 \\
\hline Trimestre 4 & $\begin{array}{c}0,1450 \\
*\end{array}$ & $\begin{array}{c}0,2272 \\
*\end{array}$ & $\begin{array}{c}0,0845 \\
* *\end{array}$ & 0,0808 & $-0,0589$ & $-0,0093$ & $-0,0114$ & 0,0512 \\
\hline Centro-Sul & $\begin{array}{c}0,3997 \\
*\end{array}$ & $\begin{array}{c}0,3417 \\
*\end{array}$ & $\begin{array}{c}0,4546 \\
*\end{array}$ & $\begin{array}{c}0,2988 \\
*\end{array}$ & $\begin{array}{c}0,4446 \\
*\end{array}$ & $\begin{array}{c}0,4065 \\
*\end{array}$ & $\begin{array}{c}0,5242 \\
*\end{array}$ & $\begin{array}{c}0,6687 \\
*\end{array}$ \\
\hline Mills & $-0,0952$ & $-0,0238$ & $-0,0997$ & 0,1647 & 0,5218 & 0,0946 & 0,0503 & $\begin{array}{c}1,3169 \\
* *\end{array}$ \\
\hline Constante & $\begin{array}{c}2,2186 \\
*\end{array}$ & 1,3547 & $\begin{array}{c}2,8433 \\
*\end{array}$ & $\begin{array}{c}2,4136 \\
* *\end{array}$ & 1,2421 & 1,2692 & $\begin{array}{c}2,5038 \\
*\end{array}$ & 1,3406 \\
\hline
\end{tabular}

Fonte: elaborada pelos autores a partir dos resultados do modelo Log-lin.

1) Significante; * $p<0,01$; ** $p<0,05 ; * * * p<0,10$. Os valores apresentados sem asteriscos não foram significativos. 2) Nas regressões quantílicas, o desvio padrão foi calculado por 100 replicações de bootstrap. 3) Os valores são os antilogaritmos dos coeficientes - [(exp-1)x100], procedimento metodológico que demonstra o efeito real dos coeficientes (Van Garderen \& Shah, 2002; Hoffmann \& Ney, 2004).

Os trabalhadores ocupados no cultivo de cana-de-açúcar da macrorregião Centro-Sul exibiram retornos positivos, os quais são superiores para os empregados nos quantis inferiores, e ganhos menores para aqueles no topo da distribuição em 2012, enquanto o inverso ocorre em 2019 (Tabela 3), o que corrobora com a teoria da segmentação (Doeringer \& Piore, 1970; Vietorisz \& Harrison, 1973, Reich et al., 1973; Lima, 1980; Taubman \& Watcher, 1986), revelando a existência da segmentação regional entre os dois locais produtores. Por exemplo, um empregado de baixa renda (quantil $10^{\circ}$ ) do Centro-Sul recebe $34,17 \%$ a mais do que um trabalhador na região Norte-Nordeste em 2012. Em 2019, esse percentual é de 40,65\%. Analisando de forma similar os trabalhadores no topo da distribuição de rendimentos (quantil $90^{\circ}$ ), em 2012 os empregados do Centro-Sul auferem 29,88\% a mais que os trabalhadores da macrorregião Norte-Nordeste, enquanto o valor para 2019 é de 66,87\% (Figura 2 e Tabela 3).

Isso indica que os empregados no cultivo de cana-de-açúcar no Centro-Sul auferem rendimentos superiores aos dos trabalhadores no Norte-Nordeste, devido ao local que exercem sua profissão, sendo em 2019 os hiatos salariais foram maiores do que em 2012. Além disso, os ganhos são maiores para os trabalhadores de remunerações médias em 2012, ao passo que, em 2019, os ganhos são superiores para aqueles que detêm altos rendimentos. 


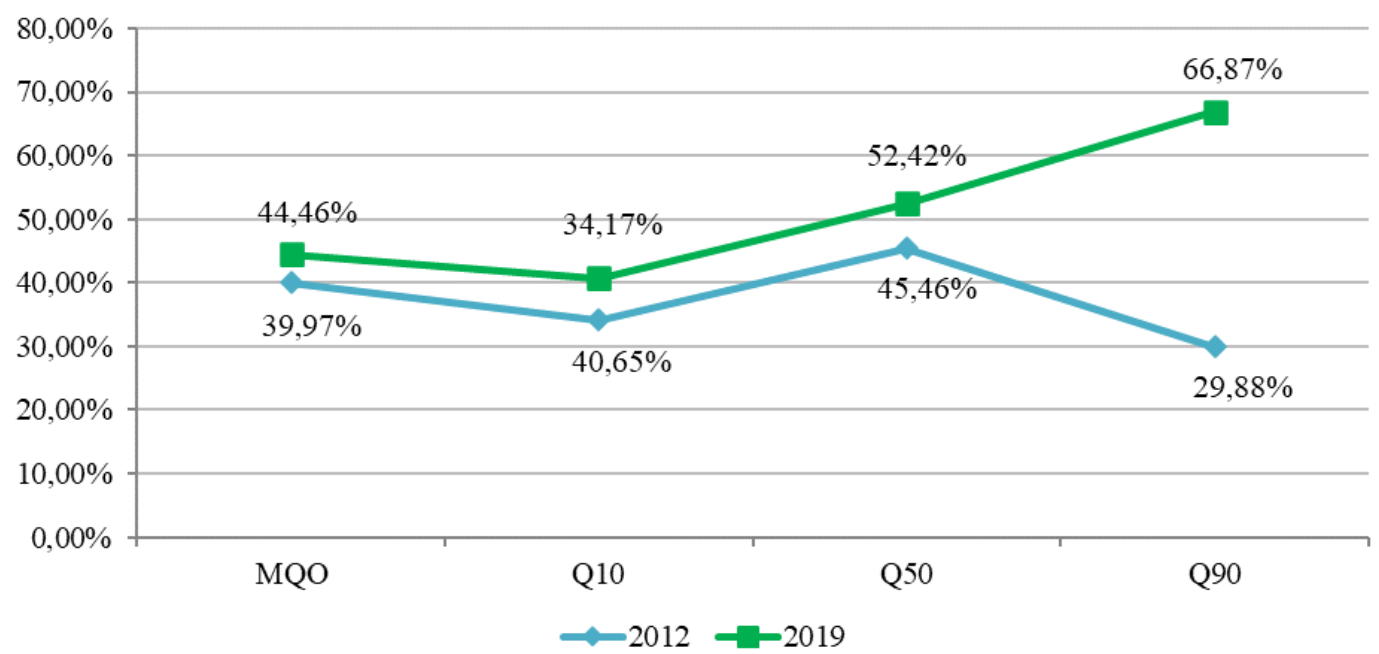

Figura 2. Diferenças salariais (\%) entre trabalhadores do Centro-Sul e Norte-Nordeste ocupados no cultivo de cana-de-açúcar - 2012 e 2019.

Fonte: elaborada pelos autores com base nos resultados do modelo Log-lin. Nota: grupo em vantagem: trabalhadores na cultura da cana-de-açúcar que residem na região Centro-Sul.

Tais dados demonstram como múltiplos fatores regionais podem influenciar a remuneração dos trabalhadores, além de suas características pessoais, como: i) novos movimentos de expansão do setor para a região Sudeste (Ferreira Filho, 2013; Feltre \& Perosa, 2020); ii) diferentes custos de vida (Menezes \& Azzoni, 2006; Almeida \& Azzoni, 2016; Departamento Intersindical de Estatística e Estudos Socioeconômicos, 2021); iii) distintos perfis tecnológicos entre as regiões, especialmente nas novas localidades produtivas no Centro-Sul (Rosário et al., 2011; Feltre \& Perosa, 2020), onde mais intensidade de tecnologia contribuiria para um aumento na produtividade do trabalhador, resultando em remunerações maiores, assim como exposto pela teoria do capital humano.

Os resultados encontrados confirmam a diferença salarial entre os trabalhadores no cultivo de cana-de-açúcar em diferentes regiões produtoras no país, em que o Norte-Nordeste caracteriza-se com menores rendimentos quando comparado à região Centro-Sul (Moraes, 2007a, 2007b; Liboni, 2009; Moraes et al., 2015). Além das particularidades regionais, constatase disparidade ao longo da distribuição de salários, em que o ano de 2012 se define com maiores desigualdades entre aqueles com rendimentos médios (quantil $50^{\circ}$ ), enquanto o ano de 2019 se qualifica com maior diferença de rendimentos no topo da distribuição (quantil $90^{\circ}$ ) (Figura 2 e Tabela 3).

\subsection{Decomposição salarial e o efeito da segmentação para os trabalhadores no cultivo da cana-de-açúcar}

Para observar o quanto dessa diferença salarial decorre das características dos trabalhadores e o quanto se origina da segmentação regional, fez-se uso da decomposição salarial de Oaxaca (1973) e Blinder (1971) para a média e para os quantis $10^{\circ}, 50^{\circ}$ e $90^{\circ}$ (Tabela 3). As diferenças salariais foram explicadas pelas particularidades dos trabalhadores, sejam elas atributos produtivos, como educação e experiência, por exemplo, sejam não produtivos, que 
correspondem à cor da pele e à ocupação e, ainda, a uma parcela a qual se refere à proxy da segmentação regional.

Tabela 4. Decomposição salarial dos trabalhadores ocupados no cultivo de cana-de-açúcar nas regiões Centro-Sul e Norte-Nordeste - 2012 e 2019

\begin{tabular}{|c|c|c|c|c|}
\hline \multicolumn{5}{|c|}{2012} \\
\hline & OB & $10^{\circ}$ & $50^{\circ}$ & $90^{\circ}$ \\
\hline \multicolumn{5}{|c|}{ Efeito explicado } \\
\hline Coeficientes & $0,1135^{*}$ & 0,0688 & $0,0839 * *$ & $0,1234 * *$ \\
\hline$\%$ & 24,81 & 14,65 & 19,38 & 26,09 \\
\hline \multicolumn{5}{|c|}{ Efeito da segmentação regional } \\
\hline Coeficientes & $0,3439 *$ & $0,4012 *$ & 0,3491 * & $0,3496 *$ \\
\hline$\%$ & 75,19 & 85,35 & 80,62 & 73,91 \\
\hline \multicolumn{5}{|c|}{ Diferença total } \\
\hline Coeficientes & $0,4574 *$ & $0,4700 *$ & $0,4330 *$ & $0,4730^{*}$ \\
\hline$\%$ & 100,00 & 100,00 & 100,00 & 100,00 \\
\hline \multicolumn{5}{|c|}{2019} \\
\hline & OB & $10^{\circ}$ & $50^{\circ}$ & $90^{\circ}$ \\
\hline \multicolumn{5}{|c|}{ Efeito explicado } \\
\hline Coeficientes & $0,2856 *$ & $0,1704 *$ & $0,1304^{*}$ & $0,4123^{*}$ \\
\hline$\%$ & 45,81 & 24,07 & 25,82 & 65,72 \\
\hline \multicolumn{5}{|c|}{ Efeito da segmentação regional } \\
\hline Coeficientes & $0,3378 *$ & $0,5376 *$ & $0,3748 *$ & $0,2150 * *$ \\
\hline$\%$ & 54,19 & 75,93 & 74,18 & 34,28 \\
\hline \multicolumn{5}{|c|}{ Diferença total } \\
\hline Coeficientes & $0,6233^{*}$ & $0,7080 *$ & $0,5053^{*}$ & $0,6273^{*}$ \\
\hline$\%$ & 100,00 & 100,00 & 100,00 & 100,00 \\
\hline
\end{tabular}

Fonte: elaborada pelos autores com base nos microdados da PNAD-C 2012 e 2019.

Notas: 1) Significante. * $p<0,01$. ** $p<0,05$. *** $p<0,10$. Os valores apresentados sem asteriscos não foram significativos. 2) Grupo em vantagem: trabalhadores na cultura da cana-de-açúcar que residem na região Centro-Sul. 3) OB: decomposição salarial de Oaxaca (1973) e Blinder (1971).

A parte não explicada ocorre por meio da diferença entre os coeficientes das regressões mincerianas dos trabalhadores inseridos no cultivo de cana-de-açúcar, que residem na região Centro-Sul ou Norte-Nordeste, quantificando a variação nos salários do grupo em desvantagem (Norte-Nordeste) ao aplicar os coeficientes do grupo em vantagem (Centro-Sul) nas características dos que estão em desvantagem (Oaxaca, 1973; Blinder, 1971). Sendo assim, a segmentação regional ocorre quando os trabalhadores agregam os mesmos atributos produtivos e não produtivos, mas o mercado de trabalho os trata de forma diferenciada em consequência da região onde residem, o que pode ser motivado pelas distintas dinâmicas econômicas, produtivas e tecnológicas presentes nas regiões, evidenciando as grandes heterogeneidades regionais.

Em 2012, o efeito explicado pelos atributos pessoais e produtivos dos trabalhadores é inferior ao efeito da segmentação regional. Na análise de Oaxaca (1973) e Blinder (1971), a parte explicada corresponde a $24,81 \%$ da diferença salarial, ao mesmo tempo que a investigação por quantis mostra que o efeito explicado cresce ao longo da distribuição de rendimentos, sendo o quantil $10^{\circ}$ responsável por $14,65 \%$ e o quantil $90^{\circ}$ motivador de $26,09 \%$ da diferença dos salários (Tabela 4 e Figura 3).

Por outro lado, o efeito da segmentação regional, isto é, o efeito que causa a disparidade de salários devido ao local em que o empregado tem domicílio, é maior para todas as 
decomposições, seja na média (OB), seja por quantis. Isto significa que a maior parte da diferença salarial entre os trabalhadores na produção de cana-de-açúcar em 2012 é gerada pelo efeito da segmentação regional. Tal efeito é superior para os trabalhadores com rendas mais baixas (quantil $10^{\circ}$ ) (Tabela 4 e Figura 3 ).

Para 2019, os comportamentos das decomposições de OB e para os quantis $10^{\circ}$ e $50^{\circ}$ se assemelham à análise de 2012, embora os percentuais sejam díspares. Dessa forma, a segmentação regional foi responsável pela maior parcela da disparidade salarial. Em contrapartida, o quantil $90^{\circ}$ expõe que o efeito da segmentação regional foi inferior ao explicado, ou seja, os atributos dos trabalhadores tiveram mais importância para explicar a diferença salarial nesse ponto da distribuição de rendimentos, isto é, os trabalhadores mais ricos (Tabela 4 e Figura 3).

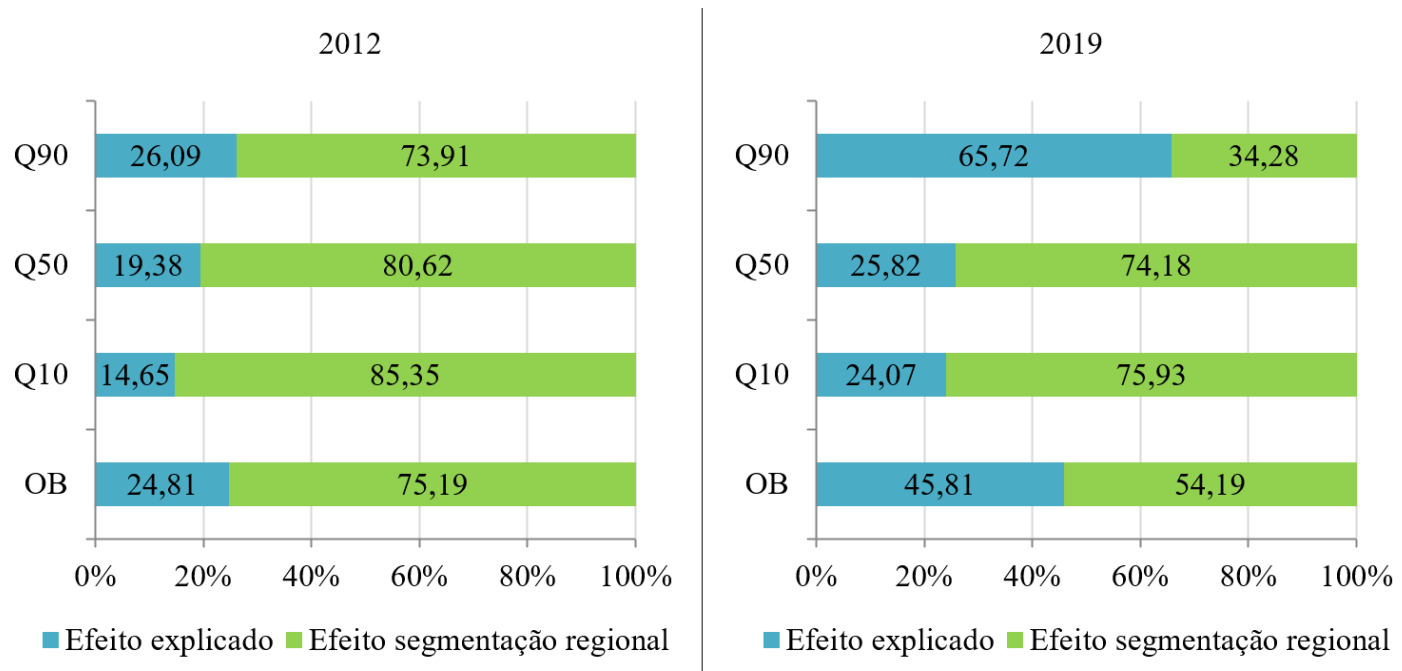

Figura 3. Decomposição salarial dos trabalhadores ocupados no cultivo de cana-de-açúcar nas regiões Centro-Sul e Norte-Nordeste - 2012 e 2019.

Fonte: elaborada pelos autores com base nos microdados da PNAD-C 2012 e 2019.

Notas: 1) Grupo em vantagem: trabalhadores na cultura da cana-de-açúcar que residem na região Centro-Sul; 2) OB: decomposição salarial de Oaxaca (1973) e Blinder (1971).

Os resultados obtidos para 2012 e 2019 comprovam a existência de diferença salarial entre os trabalhadores no cultivo de cana-de-açúcar, tendo os indivíduos que residem na região Centro-Sul apresentado remunerações superiores quando comparados aos que moram na região Norte-Nordeste (Tabela 3 e Figura 2). Ademais, características da região, como dinâmica econômica, estrutura produtiva do setor, custo de vida, intensidade tecnológica, fluxos migratórios em busca de trabalho em regiões diferentes do local de residência, ou seja, o efeito da segmentação regional, foram os grandes motivadores das disparidades de rendimentos em 2012 e 2019, exceto para o quantil 90 em 2019 (Tabela 4 e Figura 3).

Tendo em consideração o período selecionado para estudo, constata-se que em períodos dinâmicos, com baixa taxa de desemprego e crescimento econômico, particularmente do setor agropecuário - como 2012 -, ou em períodos de crise e altas taxas de desemprego como 2019 -, o efeito da segmentação regional predomina como motivação das diferenças entre as remunerações dos trabalhadores na produção de cana-de-açúcar nas macrorregiões produtoras, com exceção do quantil $90^{\circ} \mathrm{em} 2019$.

Embora os percentuais que correspondem à segmentação regional tenham diminuído entre os anos, as características individuais do trabalhador acabam sendo secundarizadas, o que 
acaba evidenciando heterogeneidades entre as duas macrorregiões produtoras, em relação à dinâmica da economia, da produtividade, da tecnologia, ao padrão de vida etc. Contudo, nota-se que os percentuais relacionados aos atributos produtivos e pessoais dos empregados aumentam de um ano para outro, o que denota valorização do capital humano destes (Tabela 3 e Figura 2). Ao compreender que a segmentação regional foi construída historicamente por questões políticas e econômicas, como visto anteriormente pelas correntes teóricas, esse efeito influencia diretamente como o mercado de trabalho remunera os indivíduos que deste participam, podendo ser examinado pelos dados das Tabelas 3 e 4 e Figuras 2 e 3 .

\section{CONCLUSÕES}

Este trabalho buscou identificar desigualdades salariais dos trabalhadores inseridos na cultura de cana-de-açúcar nas macrorregiões produtoras Centro-Sul e Norte-Nordeste e mensurar suas causas para os hiatos salariais regionais com base nos microdados da PNAD-C para 2012 e 2019.

Os resultados comprovaram a diferença salarial entre os trabalhadores das duas macrorregiões produtoras, tendo os indivíduos que moram no Centro-Sul auferido maiores salários do que os trabalhadores que residem na região Norte-Nordeste. Os hiatos foram maiores para 2019 comparativamente a 2012, assim como para aqueles com médios rendimentos (quantil $50^{\circ}$ ) em 2012. Em contrapartida, identificou-se que, em 2019, aqueles que pertencem ao topo da distribuição de rendimentos (quantil $90^{\circ}$ ) são os que possuem as maiores diferenças.

Tais dados indicam que múltiplos fatores regionais podem influenciar a remuneração dos trabalhadores, além de suas características pessoais, como circulação da mão de obra em busca de trabalho, distintos perfis tecnológicos, produtivos e econômicos e diferentes custos de vida entre as regiões. Tais fatores influenciam a produtividade do trabalhador e, consequentemente, seu rendimento.

Com respeito à decomposição salarial, contata-se que o efeito da segmentação regional é superior quando comparado com a parcela que se refere aos aspectos produtivos do trabalhador (efeito explicado). Os resultados confirmam a presença de segmentação regional no mercado de trabalho entre os trabalhadores no cultivo de cana-de-açúcar. Conclui-se que empregados com características produtivas semelhantes auferem salários diferentes devido à área onde residem e, confirmando a segmentação regional, a qual é motivada pelas particularidades regionais, evidenciando diferentes processos sociais, econômicos, produtivos e tecnológicos presentes em cada macrorregião produtora. Com isso, independentemente da dinâmica econômica do país - seja em período de crescimento (2012), seja de crise (2019) -, o grande gerador das disparidades salariais foi a segmentação regional.

Evidencia-se, pois, a complexidade do mercado de trabalho especificamente para os trabalhadores inseridos no cultivo de cana-de-açúcar, reconhecendo as dessemelhanças econômicas, sociais e até mesmo ambientais entre as áreas produtoras. Com isto, espera-se contribuir para os debates e formulações de políticas que se comprometam em amenizar o efeito da segmentação regional e melhorar as condições de trabalho desses indivíduos.

Acredita-se que os trabalhadores dispensados na produção da cana-de-açúcar sejam direcionados a outras ocupações. Indica-se a implantação de políticas públicas setoriais que visam à assistência dos empregados nesse cultivo. Alguns exemplos podem ser mencionados, como: i) programas de qualificação educacional, visto que os trabalhadores apresentam poucos anos de estudo; ii) apoio à agricultura familiar nos locais de origem dos migrantes sazonais, pois, em muitos casos, migram para trazer sustento à família e também porque não encontraram trabalho em sua cidade ou estado de origem. 
Por fim, algumas limitações do artigo podem ser mencionadas, de modo que se abrem perspectivas para estudos futuros, como: a incorporação da questão migratória, visto que um indivíduo pode residir em uma região, mas trabalhar em outra; inserção e controle de características dos trabalhadores não observadas e invariantes ao tempo, como a motivação do indivíduo; análise de gênero com o objetivo de investigar a presença ou não de discriminação contra as mulheres no cultivo de cana-de-açúcar, entre outras questões.

\section{REFERÊNCIAS}

Abreu, D., Moraes, L. A., Nascimento, E. N., \& Oliveira, R. A. (2008). Impacto social da mecanização da colheita de cana-de-açúcar. Revista Brasileira de Medicina do Trabalho, 4(Esp.), 3-11.

Almeida, A. N., \& Azzoni, C. R. (2016). Custo de vida comparativo das regiões metropolitanas brasileiras: 1996-2014. Estudos Econômicos, 46(1), 253-276.

Baccarin, J. G., Alves, F. J. C., \& Gomes, L. F. C. (2008). Emprego e condições de trabalho dos canavieiros do Centro-Sul do Brasil, entre 1995 e 2007. In XLVI Congresso da Sociedade Brasileira de Economia, Administração e Sociologia Rural (SOBER). Rio Branco: SOBER.

Balsadi, O. V. (2007). Mercado de trabalho assalariado na cultura cana-de-açúcar no Brasil no período 1992-2004. Informações Econômicas, 37(2), 38-54.

Bastos, E. (2019). Cana-de-açúcar e política econômica: o caso do Nordeste. Revista de Economia e Sociologia Rural, 19(1), 17-34.

Becker, G. S. (1962). Investment in human capital: a theoretical analysis. Journal of Political Economy, 70(5), 9-49.

Becker, G. S. (1971). The economics of discrimination (2nd ed.). Chicago: The University of Chicago Press.

Blinder, A. S. (1971). Wage discrimination: reduced form and structural estimates. The Journal of Human Resources, 8(4), 436-455.

Botelho, F., \& Vladimir, P. (2011). Segmentation in the Brazilian labor market. Economic Development and Cultural Change, 59(2), 437-463.

Brasil, Ministério do Trabalho e Emprego. (2017). Dados e Estatísticas. Relação Anual de Informações Sociais - RAIS, Brasília.

Brasil. (2000). Lein 10.097 de 19 de dezembro de 2000. Lei ordinária: Artigos 402 e 403. Brasília. Recuperado em 17 de março de 2021, de http://www.planalto.gov.br/ccivil_03/leis/110097.htm

Cacciamali de Souza, M. C. (1978). Mercado de trabalho: abordagens duais. Revista de Administração de Empresas, 18(1), 59-69.

Centro de Estudos Avançados em Economia Aplicada - CEPEA. (2017). Recuperado em 01 de abril de 2019, de https://www.cepea.esalq.usp.br/br/pib-de-cadeias-agropecuarias.aspx/

Cirino, J. F., \& Lima, J. E. (2012). Diferenças de rendimento entre as regiões metropolitanas de Belo Horizonte e Salvador: uma discussão a partir da decomposição de Oaxaca-Blinder. Revista Economica do Nordeste, 43(2), 371-389.

Cunha, M. S. (2008). Os empregados da agricultura brasileira: diferenciais e determinantes salariais. Revista de Economia e Sociologia Rural, 46(3), 597-621.

Departamento Intersindical de Estatística e Estudos Socioeconômicos - DIEESE. (2021). Recuperado em 17 de março de 2021, de https://www.dieese.org.br/cesta/ 
Doeringer, P. B., \& Piore, M. J. (1970). Internal labor markets and manpower analysis. Cambridge: Harvard University, MIT.

Estanislau, P., Deon, L. E., \& Shikida, P. F. A. (2008). Composição do mercado de trabalho formal da agroindústria canavieira do Estado do Paraná (1995 a 2008). Cadernos de Economia, 2(23), 125-148.

Feltre, C., \& Perosa, B. B. (2020). Governança no setor sucroalcooleiro: uma análise comparada de São Paulo e do Cerrado Mineiro e Goiano. Economia Ensaios, 35(2), 25-48.

Fernandes, C. B. S., Shikida, P. F. A., \& Cunha, M. S. (2013). O mercado de trabalho formal no setor sucroalcooleiro no Brasil. Redes, 18(2), 177-192.

Ferreira Filho, J. B. S. (2013). Food security, the labor market, and poverty in the Brazilian bio-economy. Agricultural Economics, 44(Suppl. 1), 85-93.

Food and Agriculture Organization of the United Nations - FAO. (2019). Recuperado em 20 de Janeiro de 2019, de http://www.fao.org/faostat/en/\#data

Gomes, M. R., \& Souza, S. C. I. (2018). Assimetrias salariais de gênero e a abordagem regional no Brasil: uma análise segundo a admissão no emprego e setores de atividade. Revista de Economia Contemporânea, 22(3), 1-31.

Heckman, J. J. (1979). Sample selections bias as a specification error. Econometrica, 47(1), 153-161.

Hoffmann, R., \& Ney, M. G. (2004). Desigualdade, escolaridade e rendimentos na agricultura, indústria e serviços de 1992 a 2002. Economia e Sociedade, 13(2), 51-79.

Hoffmann, R., \& Oliveira, F. C. R. (2008). Remuneração e características das pessoas ocupadas na agro-indústria canavieira no Brasil, de 2002 a 2006. In XLVI Congresso da Sociedade Brasileira de Economia, Administração e Sociologia Rural (SOBER). Rio Branco: SOBER.

Instituto Brasileiro de Geografia e Estatística - IBGE (2012). Pesquisa Nacional por Amostra de Domicílio - Contínua (PNAD-C). Rio de Janeiro: IBGE. Recuperado em 7 de julho de 2020, de http://www.ibge.gov.br

Instituto Brasileiro de Geografia e Estatística - IBGE (2018). Pesquisa Nacional por Amostra de Domicílio - Contínua (PNAD-C). Rio de Janeiro: IBGE. Recuperado em 7 de julho de 2020, de http://www.ibge.gov.br

Instituto Brasileiro de Geografia e Estatística - IBGE. (2020). Pesquisa Nacional por Amostra de Domicílio - Contínua (PNAD-C) - séries históricas. Rio de Janeiro: IBGE. Recuperado em 14 de abril de 2020, de https://www.ibge.gov.br/estatisticas/sociais/trabalho/17270-pnadcontinua.html?edicao=26413\&t=series-historicas

Instituto de Pesquisa Econômica Aplicada - IPEA. (2020). Base de Dados do Instituto de Pesquisa Econômica Aplicada. Recuperado em 10 de julho de 2020, de http://www.ipeadata.gov.br

Junior, R. T., \& Liboni, L. B. (2008). Evolução recente do mercado de trabalho da cana-de-açúcar no Brasil (1995-2006). Organizações Rurais \& Agroindustriais, 10(3), 455-474.

Koenker, R., \& Basset, G. (1978). Regression Quantiles. Econometrica, 46(1), 33-50.

Liboni, L. B. (2009). Perfil da mão-de-obra do setor sucroalcooleiro: tendências e perspectivas. (Tese de doutorado). Universidade de São Paulo, São Paulo.

Lima, J. P. R., \& Melo, L. C. P. (1989). Cana-de-açúcar no Nordeste; ostracismo tecnológico, caminhos alternativos e rebatimentos regionais. In Anais do 17 Encontro Nacional de Economia. Brasília: ANPEC.

Lima, R. (1980). Mercado de trabalho: o Capital Humano e a teoria da segmentação. Pesquisa e Planejamento Econômico, 10(1), 217-272. 
Maia, K., \& Souza, S. C. I. (Orgs.). Diferenças salariais e discriminação por gênero e cor nas regiões brasileiras. Londrina: Eduel, 2019.

Mantovani, G. G., Souza, S. C. I., \& Gomes, M. R. (2021). Diferenças salariais inter e intraocupações: evidências para o Paraná e Bahia. Gestão \& Regionalidade, 37(110), 117-136.

Martins, H. H., Shikida, P. F. A., Sesso Filho, U. A., Gimenes, R. M. T., \& Calvo, J. C. A. (2016). Geração de produção, emprego e remunerações nas indústrias do açúcar e do álcool em 2000 e 2009. Desafios: Revista Interdisciplinar da Universidade Federal do Tocantins, 2(2), 198-219.

Mazzuchetti, R. N., \& Shikida, P. F. A. (2017). O comércio internacional do açúcar sob a perspectiva do modelo gravitacional. Revista de Ciências Agrárias, 40(2), 471-482.

Melly, B. (2005). Decomposition of differences in distribution using quantile regression. Labour Economics, 12(4), 577-590.

Menezes, T. A., \& Azzoni, C. R. (2006). Convergência de salários entre as regiões metropolitanas brasileiras: custo de vida e aspectos de demanda e oferta do trabalho. Pesquisa e Planejamento Economico, 36(3), 449-470.

Menezes, W. F., Carrera-Fernandez, J., \& Dedecca, C. (2005). Diferenciações regionais de rendimentos do trabalho: uma análise das regiões metropolitanas de São Paulo e de Salvador. Estudos Econômicos, 35(2), 271-296.

Mincer, J. (1958). Investment in human capital and personal income distribution. Journal of Political Economy, 66(4), 281-302.

Mincer, J. (1974). Schooling, experience and earnings. New York: National Bureau of Economic Research.

Moraes, M. A. F. D. (2007a). O mercado de trabalho da agroindústria canavieira: desafios e oportunidades. Economia Aplicada, 11(4), 605-619.

Moraes, M. A. F. D. (2007b). Indicadores do mercado de trabalho do sistema agroindustrial da cana-de-açúcar no Brasil no período 1992-2005. Revista Estudos Econômicos, 37(4), 875-902.

Moraes, M. A. F. D., Oliveira, F. C. R., \& Diaz-Chavez, R. A. (2015). Socio-economic impacts of Brazilian sugarcane industry. Environmental Development, 16, 31-43.

Neves, M. F., \& Conejero, M. A. (2007). Sistema agroindustrial da cana: cenário e agenda estratégica. Economia Aplicada, 11(4), 587-604.

Oaxaca, R. (1973). Male-female wage differentials in urban labor market. International Economic Review, 14(23), 693-709.

Orlandi, M., Netto Oliveira, L. V., Shikida, P. F. A., \& Braun, M. B. S. (2011). O mercado de trabalho formal na agroindústria canavieira de Mato Grosso: uma análise comparativa entre 1999 e 2009. Revista de Estudios Sociales, 13(26), 186-203.

Produção Agrícola Municipal - PAM. (2019). Recuperado em 11 de janeiro de 2019, de https:// sidra.ibge.gov.br/pesquisa/pam/tabelas.

Pintor, G. M. Z., Pintor, E., Cardoso, B. F., Aguilar, C. J. P., \& Shikida, P. F. A. (2015). Análise dos determinantes das exportações brasileiras do complexo sucroalcooleiro entre 2002 e 2012 através do modelo gravitacional. Economic Review, 23(1), 1-16.

Reich, M., Gordon, D. M., \& Edwards, R. C. (1973). Dual labor markets: a theory of labor market segmentation. The American Economic Review, 63(2), 359-365.

Rissardi Júnior, D. J. (2015). Três ensaios sobre a agroindústria canavieira no Brasil pósdesregulamentação. (Tese de Doutorado). Universidade Estadual do Oeste do Paraná, Toledo. 
Rosário, F., Rita, L., Costa, P., \& Lira, C. (2011). Análise comparativa da agroindústria sucroalcooleira no Sistema Regional de Inovação nas regiões Nordeste e Centro-Sul. GEPROS, 6(2), 127-142.

Santos Júnior, J. (2012). O mercado de trabalho canavieiro e as novas fronteiras de expansão: o caso de Sergipe. In Anais do XV CISO Encontro Norte e Nordeste de Ciências Sociais PréALAS. Teresina.

Schultz, T. W. (1964). O valor econômico da educação. Rio de Janeiro: Zahar Editores.

Scicchitano, S. (2012). The male-female pay gap across the managerial workforce in the United Kingdom: a semi-parametric decomposition approach. Applied Economics Letters, 19(13), 1293-1297.

Shikida, P. F. A., \& Bacha, C. J. C. (2019). Aspectos econômicos da geração de tecnologia e a utilização dos principais produtos e subprodutos da agroindústria canavieira do Brasil. Revista de Economia e Sociologia Rural, 36(2), 9-30.

Shikida, P. F. A., \& Rissardi Júnior, D. J. (2017). Evolução da agroindústria canavieira no Brasil (1990-2014): da ruptura do paradigma subvencionista à falta de planejamento. Revista Práticas de Administração Pública, 1(1), 74-99.

Shikida, P. F. A., Alves, L. R. A., \& Piffer, M. (2000). Estratégias tecnológicas na agroindústria canavieira do Paraná. Revista de Administração da Universidade Federal de Lavras, 2(1), 11-21.

Silva, G. C., Goulart, D. F., Xavier, B. T. L., Costa, J. C., Oliveira, F. J., \& Musser, R. S. (2006). Produtos e subprodutos da cana-de-açúcar: o PET/Agronomia/UFRE e o agronegócio numa ação de extensão. In Anais do XI ENAPET. Florianópolis: ENAPET.

Smith, A. (1983). A riqueza das nações. São Paulo: Abril Cultural.

Solimano, A. (1988). Mercado de trabalho: quatro enfoques em busca de um paradigma. Pesquisa e Planejamento Economico, 10(1), 217-272.

Staduto, J. A. R., \& Maldaner, I. S. (2010). Dispersão do rendimento do trabalho entre as regiões metropolitana e não metropolitana do Estado do Paraná. Ensaios FEE, 31(2), 451-476.

Taubman, P., \& Watcher, M. (1986). Segmented labor markets. In O. Ashenfelter \& R. Layard (Eds.). Handbook of Labor Economics (pp. 1183-1217). Amsterdam: Elsevier.

União da Agroindústria Canavieira de São Paulo - UNICA. (2019). Recuperado em 11 de janeiro de 2019, de http://www.unicadata.com.br

Van Garderen, K. J., \& Shah, C. (2002). Exact interpretation of dummy variables in semilogarithmic equations. The Econometrics Journal, 5(1), 149-159.

Vietorisz, T., \& Harrison, B. (1973). Labor market segmentation: positive feedback and divergent development. The American Economic Review, 63(2), 366-376.

Wissmann, M. A., \& Shikida, P. F. A. (2017). Impactos econômicos, ambientais e sociais da agroindústria canavieira no Brasil. Desenvo/vimento Fronteiras e Cidadania, 1(1), 134-160.

Xavier, C. A. C., Couto, M. L. P., \& Trindade, J. R. (2017). As relações de trabalho no setor sucroalcooleiro nordestino no século XXI: modernização e permanência da superexploração do trabalho. Revista de Ciências do Trabalho, 9, 43-64. 